\title{
Ecosystem Readiness: Blockchain Adoption is Driven Externally
}

\author{
Michael Lustenberger ${ }^{1 *}$, Saša Malešević ${ }^{1}$ and Florian Spychiger ${ }^{1,2}$ \\ ${ }^{1}$ School of Management and Law, Institute for Organizational Viability, Zurich University of Applied Sciences, Winterthur, \\ Switzerland, ${ }^{2}$ Institute of Informatics, Blockchain and Distributed Technologies, University of Zurich, Zurich, Switzerland
}

\section{OPEN ACCESS}

Edited by:

Avishek Nag,

University College Dublin, Ireland

Reviewed by:

Remo Pareschi,

University of Molise, Italy

Hrvoje Stancic,

University of Zagreb, Croatia

*Correspondence:

Michael Lustenberger luse@zhaw.ch

Specialty section:

This article was submitted to Blockchain in Industry,

a section of the journal

Frontiers in Blockchain

Received: 04 June 2021 Accepted: 02 August 2021 Published: 16 August 2021

Citation:

Lustenberger M, Malešević S and Spychiger $F$ (2021) Ecosystem Readiness: Blockchain Adoption is

Driven Externally.

Front. Blockchain 4:720454. doi: $10.3389 / f b / o c .2021 .720454$
Blockchain technology has been extensively tested, implemented, used, or even abandoned by organizations. Whether organizations adopt blockchain technology depends on many factors. Previous literature has identified a range of potential factors affecting the adoption of blockchain technology, but most studies have focused solely on a subset of specific factors. As a result, these studies can provide only limited explanations for the varying degrees of blockchain adoption. By relying on the well-established Technology-Organization-Environment (TOE) framework, we propose an extended Blockchain Adoption Model (BAM). We derive a rich set of factors from the current state of research on blockchain adoption and the business ecosystem literature and extend them by conceptual reasoning. We then develop testable hypotheses for each of the identified factors. The resulting 14 hypotheses are tested by conducting a survey $(n=$ 350) within the DACH-region (Germany, Austria and Switzerland). We quantitatively analyze our BAM with a binary logistic regression analysis and identify six constructs impacting the adoption (relative advantage, observability, organizational age, external stakeholder pressure, regulatory uncertainty, and scope of business ecosystem). Based on our findings we introduce the novel idea of "ecosystem readiness" as the most important factor for the adoption of blockchain. Ecosystem readiness is characterized by the following attributes: 1) a large ecosystem scope, 2) stakeholders that are not yet collaborating in a trustful and regulated environment, and 3) a powerful organization leading the ecosystem. This powerful organization further intentionally promotes innovation by 4) making the benefits of this new technology observable for others, by 5) putting pressure on the other ecosystem participants to adopt the new technology, and eventually by 6) striving for regulatory certainty in the application and use of blockchain.

Keywords: blockchain, TOE, adoption, ecosystem, readiness, BAM, survey, stakeholder

\section{INTRODUCTION}

The phenomenon of globalization has transformed the global economy. Diminishing national trade barriers, increased mobility, and a diffusion of innovative technologies on an international scale has led to the consolidation of existing markets and to the emergence of new industries (Wiersema and Bowen, 2008). These circumstances have led to a surge of competition between firms and revealed an unexpected threat posed by market newcomers from different industries. To retain their market position and maintain sustainable growth, executives are forced to respond to growing challenges and to adapt corporate strategies and operations. In doing so, companies attempt to establish a competitive advantage by seeking innovative solutions, enhancing efficiency of existing processes, or 
increasing quality of their service (Porter, 1980; Barney, 1991; Distanont, 2020). New technologies play a special role and have the potential to disrupt current processes, markets or industries (Christensen, 2013). An example of such an innovative technology was presented in 2008 by the pseudonym Nakamoto (2008). The introduction of a "peer-to-peer electronic cash system" based on the blockchain technology caught attention of many researchers and organizations. Convinced by the technology's potential, they began to explore its complex structure and to create business use cases (Glaser, 2017). As a result, multiple organizations and entrepreneurs from various industries and backgrounds developed numerous blockchain-based concepts (Tapscott and Tapscott, 2016; Bocek et al., 2017; Rauchs et al., 2019; Lustenberger et al., 2020; Malešević et al., 2020). In 2019, Deloitte questioned 1,386 executives from 13 countries regarding blockchain technology (Budman et al., 2019). The survey reveals that the technology is steadily approaching a maturation stage. The hypothetical proposals have become feasible business cases. Furthermore, executives recognized the actual advantages and potentials for their enterprises, along with emerging challenges, drawbacks, and limitations. Regardless of these obstacles, the great majority of enterprises remains optimistic regarding blockchain in general and specifically the significant capital invested in the developped blockchain projects. Despite the positive view on this new technology, companies are conservative with respect to the implementation of blockchain projects. According to Deloitte's survey, only 23 per cent of surveyed executives had started to deploy blockchain projects (Budman et al., 2019). Consequently, even though many use cases and potential applications of this new technology have emerged, only some have been implemented and are running in a productive environment (Rauchs et al., 2019). Several studies have tried to explain this low adoption of blockchain by referring to the lack of blockchain awareness and understanding (Kamble et al., 2019; Lacity and Khan, 2019), to the missing technology maturity (Iansiti and Lakhani, 2017), or to the unsolved tensions between the needed investments and the achieved benefits of blockchain (Sternberg et al., 2020). However, by focusing only on organisation-internal factors influencing the decision to adopt blockchain, these studies can provide valuable but only limited explanations for the observed phenomenon of low blockchain adoption in organizations. Barnes and Xiao (2019) developed an extended model for the adoption of blockchain based on the Technology-Organization-Environment (TOE) framework that also considers ecosystem-related factors (Depietro et al., 1990). Nevertheless, their work remains only theoretical, since no hypotheses were empirically evaluated. A further paper was published by Choi et al. (2020). Next to developing hypotheses, they also empirically tested them. However, their work features certain limitations. Instead of describing the adoption across all fields, they focused strongly on supply chains. Furthermore, their hypotheses do not question which factors influence the adoption of blockchains, but which factors affect an organization's resistance to adopt blockchain. Lastly, they base their calculation on a rather small sample size of 83 participants (Choi et al., 2020).
Therefore, there is clearly missing an extensive, empirical understanding about the factors influencing the adoption of blockchain across all industries and sectors. Understanding this is a prerequisite to discuss and explain the phenomenon of low adoption rates of blockchain in organizations. Furthermore, with these new insights and knowledge, one might be even capable to define some actions to increase the adoption of blockchain. It is therefore the objective of this study to develop a blockchain adoption model (BAM) from a wider perspective with the aim to explore the factors influencing the adoption and to conduct an empirical study in the DACH-region (Germany, Austria and Switzerland).

With the purpose to develop the blockchain adoption model BAM, this research will first answer the following research question:

RQ1: What factors influence the decision to adopt blockchain technology in organizations?

With the aim to develop afterwards empirically testable hypotheses, the second research question is:

RQ2: How do these factors affect the decision to adopt blockchain technology in organizations?

Based on the BAM and the developed hypotheses, we then conduct an empirical survey in order to find answers to our third research question:

RQ3: How can the observed low adoption rate of blockchain technology in organization be explained?

We build the BAM on the basis of the well-established and extensively used TOE framework with the aim to cover all theoretically relevant blockchain adoption factors (RQ1) and develop hypotheses on how these factors influence an organization's decision to adopt blockchain (RQ2). To test the hypotheses and to explain the reasons behind the low level of adoption (RQ3), we conduct a survey.

The remainder of this paper is structured as follows. In section 2, we elaborate on the current state of blockchain adoption. In section 3, we create our conceptual research model and state our hypotheses. Afterwards in section 4, we detail a research method to quantitatively analyze the formulated hypotheses, whereas in section 5 we present the results of the empirical survey. In section $\mathbf{6}$, we discuss the findings and, finally, in section 7 we conclude.

\section{BLOCKCHAIN ADOPTION}

\subsection{Background}

Crosby et al. (2016) characterize blockchain as a "distributed database of records, or public ledger of all transactions or digital events that have been executed and shared among participating parties". One of the most important features of blockchains is their distributed consensus mechanism. It allows several dispersed (and potentially malicious) network participants to ensure the integrity and correctness of the performed transactions. Since the introduction of blockchain and distributed ledger technologies (DLT), researchers have developed numerous consensus algorithms that provide diverse features, depending on the demands of potential 
application or requirement of users (Sun et al., 2018). The design or selection of a specific set of rules determines the attributes of a network, among others its accessibility, security, speed of validation, and number of simultaneous transactions. Blockchains not only differ in the consensus algorithms, but in many other design components (Spychiger et al., 2021). As Garriga et al. (2021) points out, the features of different blockchain technologies are important and the architectural trade-offs have an impact on cost, time-to-market and return on investment. They propose a useful framework to explore the interplay between technological decisions and architectural features. Palma et al. (2021) extend this framework to private and consortium blockchains and make thereby an important contribution since most industrial projects are built on permissioned blockchains (Vadgama and Tasca, 2021).

With the increased research invested into the exploration of technical characteristics of blockchains, as well as into the potential business opportunities, the benefits of using the technology became more obvious. Rauchs et al. (2019) identify five main benefits which could be achieved by deploying blockchain or DLT network in organizations. First, they name the generation of new business models and new revenue streams. Secondly, they state the possibility to improve efficiency of internal and external business operations. Third, thanks to the decentralization and innovative consensus mechanism a higher transparency will be possible. Fourth, they mentioned that through the disintermediation cost savings can be achieved. Lastly, they state that the security within the system increases. Even though a great (or even disruptive) economic potential is attributed to blockchain technology (Tapscott and Tapscott, 2016; Iansiti and Lakhani, 2017), the adoption of this technology by organizations is low and very often not successful (Clohessy and Acton, 2019; Lacity and Khan, 2019). The adoption of blockchain in organizations is typically following the four phases from exploration, proof-of-concept, pilot and deployment (Rauchs et al., 2019) whereby many adoption projects are stopped before reaching the final deployment phase (Baruffaldi and Sternberg, 2018). This phenomenon of low adoption rate of blockchain in practice is asking for further investigation with the aim to gain more insights and understanding regarding the usefulness and value of this new technology.

\subsection{Related Work}

The literature about specific factors influencing the adoption of the blockchain technology by organization is still in its infancy and has only recently begun to gain momentum. Koens and Poll (2018), Angelis and da Silva (2019), Werner et al. (2020) as well as Schuetz and Venkatesh (2020) define several value drivers for the adoption of blockchain, whereas they mainly focus on the blockchain specific technical characteristics like open access, decentralized consensus, immutability and distributed verification to explain why or why not the adoption of blockchain can generate values like transparency, efficiency and disintermediation to users. This strong focus on the (perceived) value of blockchain is in line with the Technology Acceptance Model (TAM) (Davis, 1985) and its emphasis on perceived usefulness and perceived ease of use to explain why users accept and use a technology.

On a similar theoretical base and with a strong focus on the individual perception of a new technology, Queiroz and Fosso Wamba (2019) investigate the factors influencing the individual blockchain adoption behavior in logistics and supply chains in India and the United States. As the foundation for their study they use a slightly altered UTAUT (Unified theory of acceptance and use of technology) model (Venkatesh et al., 2003), which helps them to draw eight hypotheses. The evaluation of their hypotheses with the partial least squared structural equation modeling (PLS-SEM) proved high differences in blockchain adoption behavior between India and the United States. The authors attribute these rather inexplicable results to the low awareness of blockchains in both countries and stress that further studies are needed to understand better the phenomena of blockchain adoption.

The explanatory potential of TAM and the associated technology adoption frameworks have been widely criticized due to their simplicity (Bagozzi, 2007), especially in an organizational context (Ajibade, 2018). Various researchers have therefore tried to study technology innovations from a more holistic perspective including organizational, technological and environmental factors that contribute to an organization's decision to adopt or to not adopt an IT innovation (Baker, 2011). One framework that is often used to examine and explain an organization's decision to adopt an IT innovation is the Technology-Organization-Environment (TOE) framework by Depietro et al. (1990). With the aim to investigate the impact of organizational factors on the adoption of blockchain in companies from a broader theoretical perspective, Clohessy and Acton (2019) applied the TOE framework in their case study research. Through a comprehensive literature review, the authors identified the most influential organizational factors on blockchain adoption, which they subsequently evaluated empirically in a multiple-case study. According to their results top management support and organizational readiness are enablers for blockchain adoption, whereas large organization are more likely to adopt blockchain than small. The technological and environmental factors have not been further analyzed. Based on an extensive literature review, Janssen et al. (2020) state that blockchain adoption has been mainly analyzed from a technical perspective. Hence, they propose a more holistic framework for the introduction of blockchain technology that captures the complex relationships between institutional, marketrelated and technical factors. The authors make explicit that the institutional, market-related and technical factors presented in their framework interact and mutually influence each other and that, depending on the context, different results are possible. However, the factors' interaction and the context's influence on the adoption are not further explained. Following the theoretical considerations of Iacovou et al. (1995) regarding the adoption of inter-organizational technologies, Sternberg et al. (2020) investigate based on a single-case study the influence of perceived benefit/cost, organizational readiness/immaturity and external pressure/resistance on the adoption of blockchain. Their analysis reveals that several tensions between different positive 
and negative factors exist that cannot be easily resolved. In summery, the authors state that in order to realize the proposed network benefits of transparency and trust, all organizations need to invest in new capabilities and overcome privacy concerns, which again can only be achieved by high longterm commitments and pre-existing inter-organizational trust. According to Sternberg et al. (2020), many blockchain adoption attempts will fail because of this paradoxical tensions. However, as their findings are based on a single-case study, the authors recognize the limited generalizability of their results and propose further research. From an ecosystem perspective and on the base of the TOE framework, Barnes and Xiao (2019) develop a comprehensive research model that examines how different technological (i.e., perceived usefulness, compatibility, relative advantage, complexity, and scope of technology), organizational (i.e., top management support, organizational readiness, firm size, and firm centralization), and environmental ecosystem actors (i.e., business competition, trading partner support, technology vendor support, governmental support, and customer support) influence organizational adoption of blockchain technology. Even though their developed research model and hypotheses are interesting, to the best of our knowledge, they have not been further empirically tested. It is therefore still open and not yet tested, if and how these factors are influencing the adoption rate of blockchain in organizations.

\section{BLOCKCHAIN ADOPTION MODEL}

\subsection{TOE Framework}

From the limited literature available about blockchain adoption in organizations, it seems that the TOE framework provides the most adequate theoretical concept for a broader empirical analysis of the factors influencing the adoption of blockchain technology in organizations as it takes into account not only technological but also organizational and environmental factors. The TOE framework was developed and introduced in 1990 by Depietro et al. (1990). This theoretical concept describes how an innovation is adopted from a firm perspective and how these three aspects-technological, organizational, and environmental-influence the decision to adopt. The technological factors include the characteristics of all available technological solutions important for a company in particular conditions. The organizational factors relate to the volume and quality of available internal resources, size of the enterprise, internal communication, and relation between different structures. And lastly, the environmental factors include firm's external situation, along with characteristics of the industry, status of the support infrastructure, and current regulations-or in other terms, its ecosystem (Moore, 1999).

To assess the technological factors of blockchain adoption, this paper considers the five perceived attributes of innovations that are relevant for the diffusion and have been popularized by Rogers (2003). These five attributes are relative advantage, compatibility, complexity, trialability, and observability. For the assessment of the organizational factors, we consider the findings by Clohessy and Acton (2019) and extend them by further conceptual reasoning. The environmental factors are influenced by the conceptual thoughts of Barnes and Xiao (2019) as well as the business ecosystem theory (Moore, 1999; Jacobides et al., 2018).

\subsection{Technological Factors}

In the context of innovation, Rogers (2003) identifies relative advantage as the most decisive explanatory factor for the speed an innovation is adopted by members of a social system. Rogers (2010) defined relative advantage as "the degree to which an innovation is perceived as being better than the idea it supersedes" ( $p$. 212). Relative advantage can be understood as a relation between foreseen benefits compared to prerequisite costs of switching to the new technology. Rogers (2003) found that the perceived benefits of a new technology depend on the nature of the innovation and the character of the adopting party. Therefore, different industries and different companies recognized specific advantages of blockchain based on their individual expectations (Carson et al., 2018). Prerequisite costs of adoption include all change efforts, monetary and otherwise, that an enterprise must make in order to implement and manage a new solution. These costs could vary as a function of a technology's maturity. Then, as Bessen (2002) note, high adoption costs could arise from switching to modern, newly developed technologies, since they required often new, scarce know-how, contemporary firm structures, or advanced soft- and hardware. Because blockchain is a relatively new and incompletely understood technology, using it to replace current business processes could generate substantial initial costs (Deshpande et al., 2017). All of this implies that an organization that sees the blockchain as more advantageous than its current solution (more benefits, less cost) is more likely to adopt this new technology.

Hypothesis 1: Relative advantage positively affects the decision of an organization to adopt blockchain technology.

The second aspect of innovation diffusion is compatibility. This attribute explains the extent to which an innovation matches the existing values, past experiences, and/or requirements of an adopter. As Rogers (2003) emphasizes, many perceived attributes can be applied universally to the majority of cases but should be also extended and considered according to the distinct technologies and adopters. Therefore, different industries or organizations could require diverse specifications or features of blockchain in order to comply with regulatory or technical demands. In respect to the blockchain adoption, it seems that apart from failures to realize tangible benefits, mainly concerns about the technical incompatibility of the blockchain with current requirements for confidentiality, privacy and data protection led to the termination of projects (Rauchs et al., 2019). Additionally, considering the large number of available blockchains and standards, it can be difficult for companies to assess the compatibility of the current infrastructure with blockchain and to take appropriate measure to adjust it to the demands of the new technology (Holotiuk and Moormann, 2018). Consequently, it is more likely that blockchain technology will be adopted by an organization if it is compatible with its established infrastructure, values and requirements. 
Hypothesis 2: Compatibility positively affects the decision of an organization to adopt blockchain technology.

The third attribute of an innovation impacting the adoption is complexity. Complexity is a subjective understanding of the innovation's functionality. Rogers (2003) suggested that complexity was less important than perceived advantage and compatibility, but for several technologies, it could be a barrier to wider diffusion. Due to its use of cryptography and novel mathematical algorithms, blockchain has been perceived by many as difficult to understand, and it causes uncertainty among legal authorities and potential technology receivers (Drescher, 2017). According to Drescher (2017), a lack of understanding and legal concerns often favors a centralized business solution provided by a trusted third party. Accordingly, the more complex the blockchain technology appears, the less likely an organization will adopt it.

Hypothesis 3: Complexity negatively affects the decision of an organization to adopt blockchain technology.

Rogers (2003) defined trialability as a further factor, which is the extent to which an innovation could be tested on a small-scale prior to an implementation. The more opportunities there are to assess a new technology, the more likely it is to be adopted, contingent on the innovation's maturity. Early adopters, enterprises attempting to accept a new, unapproved solution, perceive trialability as more crucial than late adopters (Rogers, 2003). The immaturity of blockchain was considered as a decisive determinant for enterprises to postpone further development of an actual proof of concept until crucial technological issues will be solved (Schmitt et al., 2019). Further, Clohessy and Acton (2019) concluded that the opportunity to experiment with blockchain technologies "on the cloud" prior to the introduction positively influences the adoption decision. We therefore claim that the higher an organization's perception of blockchain's trialability, the more likely it will adopt the technology.

Hypothesis 4: Trialability positively affects the decision of an organization to adopt blockchain technology.

The last technological attribute affecting an innovation's adoption is observability. This term describes how effects of an innovation are recognized and disseminated. Rogers (2003) alleged that observability of innovations varied with regards to their tangibility. As an example, he distinguished software and hardware and highlighted that attributes of hardware are more detectable than those of a software. Dobrovnik et al. (2018) indicated a difficulty at the current, immature stage of blockchain technology to observe its effects. Experience has demonstrated that for many live blockchain application, tangible commercial benefits are often only observed after the application has been in operation for a while, and therefore, due to a lack of observable results, a significant number of blockchain projects are discontinued before they have had a chance to demonstrate their potential (Rauchs et al., 2019). Consequently, the more visible the (positive) results of blockchain technology adoptions to an organization, the more likely the organization will adopt the technology.

Hypothesis 5: Observability positively affects the decision of an organization to adopt blockchain technology.

\subsection{Organizational Factors}

According to Lalic and Marjanovic (2010) implementing innovations in business processes is a complex, an ongoing procedure and a challenge for managers and entire enterprises. Therefore, fostering successful adoption of new concepts requires preparing the entire organization for the forthcoming change. The extent to which an organization can adapt their culture, resources, structures and, processes for the demands of the intended rearrangement determines the readiness of an organization for change (Weiner, 2009). Organizational readiness can be assessed by the availability of financial and technological resources for the adoption (Iacovou et al., 1995). This refers on the one hand to the financial resources that an organization allocates to new technologies (Weiner, 2009) and on the other hand to an organization's IT knowledge and experience of adopting a new technology (Wang et al., 2010). In their research, Clohessy and Acton (2019) determine organizational readiness as one of the most important organizational factors influencing the adoption of blockchain technology. A study from Post et al. (2018) disclosed that a deficiency of fundamental knowledge of the blockchain technology was one decisive reason negatively influencing the adoption of blockchain. Absence of internal knowledge and abilities was also declared as a major drawback to blockchain adoption in the survey of Rauchs et al. (2019). We conclude therefore that an organization with higher organizational readiness with respect to financial resources and IT competences is more likely to adopt blockchain technology.

Hypothesis 6: Organizational readiness positively affects the decision of an organization to adopt blockchain technology.

Based on a comprehensive meta-analysis, Lee and Xia (2006) recognized that larger enterprises tend to adapt IT innovations more easily than small to medium-sized enterprises (SME), due to their greater working power, broader knowledge skills, more advanced facilities, as well as more feasible investment ability. Organizational size has been characterized by means of controlled assets, sales level, quantity of performed transactions or produced items, but the most common measure for the size of a business is the number of full-time employees (Bose and Luo, 2011). However, even though SMEs face more barriers to adopt IT innovations, their more elastic and controllable structures and ease to join alliances could positively contribute to accommodate new technologies (Lee and Xia, 2006). Considering the blockchain perspective, three interviewees in the survey from Post et al. (2018) stated that enterprises with more complex structures and processes could experience greater challenges to implement blockchain-based solutions into their business routines. Taking cloud computing technology as an example, Clohessy et al. (2017) indicated that smaller firms, due to their lower rigidity, were able to employ specific solutions more easily than large corporations. Despite the fact that influence of organizational size on technology adoption has been discussed controversially in the literature, results from a recent case study in respect to blockchain adoption (Clohessy and Acton, 2019) indicate a positive relation between organizational size and the adoption. Accordingly, we expect that the larger the size of an organization, the more likely it will adopt blockchain technology. 
Hypothesis 7: Organizational size positively affects the decision of an organization to adopt blockchain technology.

Top management support has been identified as a key factor for the success of IT innovation projects (Young and Jordan, 2008). Dong et al. (2009) specified top management support as supportive behaviors of managers and analyzed their influence on implementation quality and effectiveness. According to the authors, three managerial behaviors are the main factors affecting the implementation of new technology solutions: 1) supporting the overcoming of change barriers and resistance, 2) creating and sharing a long-term vision, and 3) efficient provisioning and allocating of needed resources. Stemberger et al. (2011) further highlight that top management support primarily means to be aware of the importance of a technology for the organization, and to actively participate in planning and executing of the technology adoption activities. Based on the empirical results by Clohessy and Acton (2019) showing that top management support has a positive influence on blockchain adoption, we conclude that the higher the top management support regarding blockchain technology, the more likely an organization will adopt it.

Hypothesis 8: Top management support positively affects the decision of an organization to adopt blockchain technology.

Balasubramanian and Lee (2008) analysed how the age of a company influences its innovation quality. Their initial hypothesis was that the age influences innovation quality negatively, meaning that the quality of innovation falls with firm age. Later, by performing empirical tests they were able to confirm that hypothesis. A further study was published by Knight and Cavusgil (2004), who showed that younger companies implement product innovations in order to break into a market. Additionally, the administrative burden is smaller for younger companies and therefore they can act faster and more pragmatic. However, to the best of our knowledge, there are no studies exploring the effect of the company age on the blockchain adoption. As Clohessy and Acton (2019) analyzed, the majority of blockchain adoption studies focused on the organisational readiness, senior management support or organisational size. They were not able to find studies concerning the company's age. Nevertheless, based on the findings of Balasubramanian and Lee (2008) and Knight and Cavusgil (2004) we propose that the organisational age negatively influences the adoption of blockchain.

Hypothesis 9: Organisational age negatively affects the decision of an organization to adopt blockchain technology.

\subsection{Environmental Factors}

Among the proposed environmental factors in the original TOE framework are industry characteristic and market structure (Depietro et al., 1990) which can be captured by the competition intensity (Baker, 2011). The intensity of competition is a central element in Porter's five forces framework and describes the extent to which other market participants affect a company's behavior (Porter, 1980). The impact of competition was, according to the author, increasing on the stagnant markets with large number of homogeneous firms and immense difficulties to exit. The theory asserted that a high intensity of rivalry had a positive impact on incentivizing firms to innovate (Sharpe and Currie, 2008; Vives, 2008). IT innovations in competitive conditions could play a significant role to retain a company's market position by surging efficiency of business processes. Consequently, it would allow a firm to distant competition by establishing a unique competitive advantage and stimulate competitors to explore new technology to prevent being outpaced (Zhu et al., 2006). This should foster the adoption of an innovative technology. Therefore, we conclude that the higher the intensity of competition, the more likely an organization will decide to adopt blockchain.

Hypothesis 10: Competition intensity positively affects the decision of an organization to adopt blockchain technology.

A further factor of the environment is external pressure, which refers to the constraint from stakeholders outside an enterprise to adopt an imposed matter, for instance a particular norm, regulation, certain behavior, or a favored technology (Sarkis et al., 2010). External stakeholders include customers, competitors, trading partners, regulators, governments, investors, and non-profit organizations (Sarkis et al., 2010). In the context of information and communications technology (ICT), Penttinen and Tuunainen (2009) argued that competitors and trading partners are the most influential external stakeholders. A force that could affect extrinsically an adoption of a technology is an influence exercised by an external trading partners, for example by a crucial customer (Iacovou et al., 1995). The authors assessed that this dependency mainly applied, but not exclusively, to smaller enterprises due to their inferior market position. The research of Iacovou et al. (1995) showed that reliance on a collaboration with a strategic partner and his requirement to integrate new technology, in order to retain a partnership, could foster its adoption. These results asserted diffusion of a technology by companies despite their perception of benefits arising not directly from using a new solution (Iacovou et al., 1995). Consequently, we attribute external pressure a positive effect on blockchain adoption.

Hypothesis 11: External stakeholder pressure positively affects the decision of an organization to adopt blockchain technology.

Emerging technologies with innovative solutions and features represent regularly a great challenge for the regulator to align existing laws to the evolving demands (Piscini et al., 2018). Regulatory uncertainty can be defined as the perceived inability to predict the future state of the regulatory environment and is generally seen to have a negative influence on investment decisions by organizations (Hoffmann et al., 2009). According to Salmon and Myers (2019), the distributed character of blockchain establishes legal concerns that are not recognized by the current regulations. They further identified several essential matters that legal authorities had to address in order to affiliate distributed ledger into the existing laws, such as data protection, taxation, and anti-money-laundering regulations. Firstly, nodes inside a distributed network, for instance in a public blockchain, might be located in various judicial areas. In such circumstances, it can be presumed that an executed transaction affects different jurisdictions. This sparked concerns regarding which law should apply in such a situation. Secondly, since there is no central trusted institution 
governing a network, the question arises which party should be accountable in the event of law violation. In their analysis of several theoretical and practical use cases of blockchain in supply chain logistics, Hackius and Petersen (2017) showed that the uncertainty regarding regulations was a major drawback for the adoption of blockchain technology. Consequently, the more regulatory uncertainty an organization is exposed to, the less likely it will adopt blockchain.

Hypothesis 12: Regulatory uncertainty negatively affects the decision of an organization to adopt blockchain technology.

Blockchain-based projects are characterized by close collaboration between different stakeholders. This cooperation spans a complex range of industries, organizations and interests, making them worthwhile to study from an ecosystem perspective (Barnes and Xiao, 2019). In the ecosystem research, the emphasis is on understanding the interaction between interdependent, but legally autonomous actors creating and commercializing innovations that benefit the end-user. Often, these innovations fail if coordination within the ecosystem is insufficient (Jacobides et al., 2018). As blockchain ecosystems are built up as decentralized systems, in which rights and decision making are not concentrated in a single institution, the development and adoption of this technology provides for organizations several unique challenges such as competing blockchain standards, decentralized governance models, intellectual property concerns, confidentiality risks and regulatory uncertainty (Lacity, 2018). The relative scarcity of blockchain expertise, and the challenge of forming multidisciplinary teams composed of jurists, computer scientists, and blockchain experts, hampered multiple use cases from being deployed and diffused (Beck and Müller-Bloch, 2017). Bringing an example of regulations in the financial industry, Holotiuk et al. (2018) emphasized the need for collaboration between banks and policy makers aiming to establish a common framework for blockchain based solutions. The establishment of blockchain consortia was a reaction to the strong urgency of cooperation between involved stakeholders (Holotiuk et al., 2018). How exactly organizations work together and find solutions within these new form of collaboration are not yet fully understood (Ziolkowski et al., 2020). However, empirical results indicate that preexisting collaboration among stakeholders positively affects the adoption of blockchain (Queiroz and Fosso Wamba, 2019). Therefore, we conclude that pre-existing collaboration approaches among stakeholders will favor blockchain adoption for an organization.

Hypothesis 13: Pre-existing collaboration with other stakeholders positively affects the decision of an organization to adopt blockchain technology.

In their paper, Barnes and Xiao (2019) define the scope of a technology as a factor with negative influence on the organizational adoption of blockchain technology. By technology scope, they mean whether the technology is applied intra- or inter-organizational with the latter being larger in scope and more difficult to adopt for an organization. Although, we believe that blockchain is necessarily an inter-organizational technology developed and adopted within a collaborative network (i.e. innovation ecosystem), the scope of the network and the blockchain application can have an adverse effect on the adoption. For example, it has been demonstrated that geographical dispersion and the number of nodes have a negative influence on the adoption of collaborative approaches in supply chain networks (Holweg et al., 2005). Consequently, we expect that the wider the scope of the business ecosystem in terms of participants and geographical dispersion, the less likely an organization will adopt blockchain technology.

Hypothesis 14: Scope of the business ecosystem negatively affects the decision of an organization to adopt blockchain technology.

\subsection{Conceptual Model and Hypotheses}

The final conceptual Blockchain Adoption Model is depicted in Figure 1. The technological context consists of relative advantage, compatibility, complexity, trialability and observability. The relative advantage is affected by the perceived benefits and the costs. The organizational context has the factors organizational readiness, organizational size, senior management support and organizational age. The organizational readiness is in turn influenced by the availability of human and technological resources and by the organizational structure. The environmental context consists of competition intensity, external pressure, regulatory uncertainty, collaboration and the scope of the business ecosystem. External pressure can be further divided into competitors, customers, suppliers, regulators and shareholders. Furthermore, collaboration is divided into competitors, customers, suppliers, regulators, IT vendors and universities. The scope of the ecosystem is defined on one hand by the number of participants and on the other hand by the geographic dispersion. The impact (positive/negative) of each of those factors is also visualized in the figure. Additionally, we introduce "blockchain knowledge" as a control variable. Although Guo and Liang (2016) used blockchain knowledge as a construct within the organizational context, we decided to use it as a control variable. We base our decision on the fact that in contrast to all the above-mentioned constructs, blockchain knowledge is not a company-related construct, but a personal one. Our final hypotheses are summarized in Table $\mathbf{1 .}$

\section{METHODOLOGY}

\subsection{Questionnaire Design and Operationalization}

Methodologically this study will investigate the phenomena of low blockchain adoption rates in organizations with a comprehensive quantitative research. Therefore, we formulated assumptions in form of directional hypotheses (Creswell and Creswell, 2018), based on predictions asserted by authors of corresponding studies with a purpose of analyzing a correlation or influence of independent variables on a dependent variable. To measure and test our established hypotheses, we conduct a survey. Compared to other approaches, this method allows researchers to reach a large and geographically diverse set of respondents at low cost, 


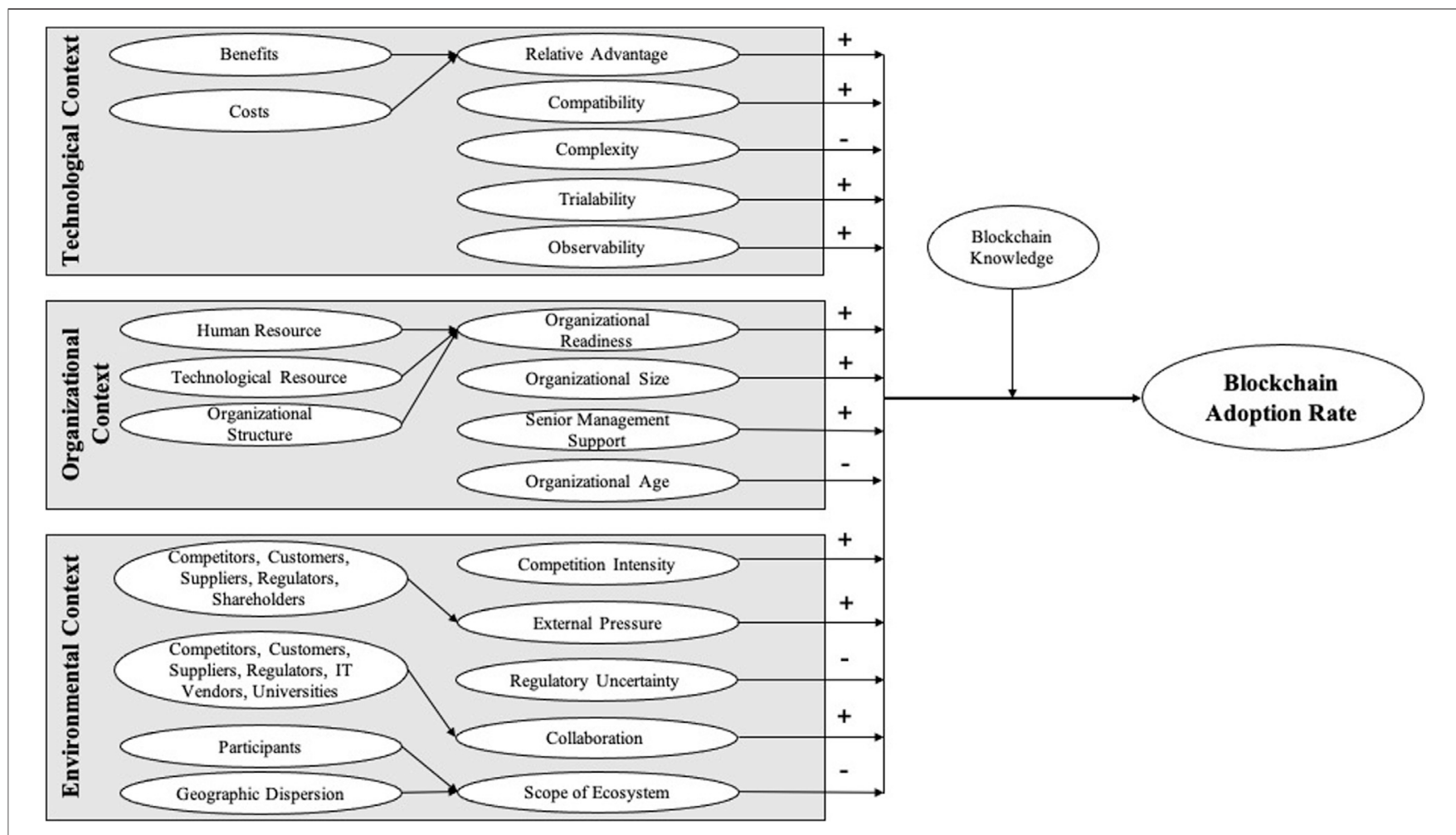

FIGURE 1 | The blockchain adoption model (BAM).

\section{TABLE 1 | Overview on all hypotheses.}

\section{Technological hypotheses}

H1: Relative advantage positively affects the decision of an organization to adopt blockchain technology $\mathrm{H} 2$ : Compatibility positively affects the decision of an organization to adopt blockchain technology H3: Complexity negatively affects the decision of an organization to adopt blockchain technology $\mathrm{H} 4$ : Trialability positively affects the decision of an organization to adopt blockchain technology H5: Observability positively affects the decision of an organization to adopt blockchain technology

\section{Organizational Hypotheses}

H6: Organizational readiness positively affects the decision of an organization to adopt blockchain technology $\mathrm{H} 7$ : Organizational size positively affects the decision of an organization to adopt blockchain technology H8: Top management support positively affects the decision of an organization to adopt blockchain technology H9: Organisational age negatively influences blockchain adoption

\section{Environmental Hypotheses}

\section{H10: Competition intensity positively affects the decision of an organization to adopt blockchain technology} H11: External stakeholder pressure positively affects the decision of an organization to adopt blockchain technology H12: Regulatory uncertainty negatively affects the decision of an organization to adopt blockchain technology H13: Pre-existing collaboration with other stakeholders positively affects the decision of an organization to adopt blockchain technology H14: Scope of the business ecosystem negatively affects the decision of an organization to adopt blockchain technology

quickly, and efficiently (Sue and Ritter, 2012). The design of survey questions, as Sue and Ritter (2012) articulate, is an important aspect of the survey process. According to Beatty et al. (2020), constructing a questionnaire consists of five phases: scoping, development, exploratory testing, quality assessment, and explanatory/data driven retesting. Scoping includes selecting the data collection channel, defining objectives, and identifying potential limitations. The questionnaire development stage concentrates on the first outline of the survey questions (Beatty et al., 2020). Furthermore, an initial self-check while composing questions should be performed. The QAS-99 provides eight potential 
points of failure while filling out a questionnaire by interviewees (Willis and Lessler, 1999). Exploratory testing and quality assessment is often done with a small group in order to gather an initial feedback. After improving the survey, a retesting is often performed. Applying this questionnaire constructing approach to our case resulted in the following steps: Qualtrix was chosen as the data collection channel. The opening part of the questionnaire includes an introduction about the subject, an explanation on the process, and a time estimation to complete it. Afterwards, part I of the survey captures general information about the organization in which the respondent works. Part II includes questions about current blockchain projects and the current stage of adoption. The definition of the current stage of adoption is based on Rauchs et al. (2019) and falls in either one of the following five categories: None, Initial Exploration, Proof of Concept, Trial or Inproduction. The answers to that question simultaneously represent the dependent variable for analysis. Part III encloses the main questionnaire, with questions about the technological, organizational and environmental context being asked. The answers to these questions represent the independent variables for our analysis. Consequently, the acceptance/rejection of hypotheses is based on the answers from part III. Part IV contains questions about the respondent and allows to collect feedback or further inputs. The entire questionnaire (except for part IV) consists of close-ended questions. To assess the questions we offered the participants a 5-point Likert scale (e.g. strongly disagree-strongly agree). An initial pretest with a small focus group was conducted to assess the quality. It gave important insights on how to improve the survey. Such insights were e.g. that the blockchain stage should contain also a "stopped" option, that the time to complete the survey was rather long and should be shortened and that some industries were missing. After improving the questionnaire, we retested it. The feedback of the improved version was very positive and allowed us to use it as the live version.

Our survey questions are strongly derived from other research as shown in Table 2. Questions asking about the companies role within a blockchain project, the stage of the blockchain project and the use case of the project are all based on Rauchs et al. (2019). For the technological constructs we were always able to find at least one very similar study, since Roger's "diffusion of innovation" theory was used by many other scholars. Therefore, our technology questions regarding relative advantage (Moore and Benbasat, 1991; Hsing Wu et al., 2013), compatibility (Moore and Benbasat, 1991; Wang et al., 2010), complexity (Wang et al., 2010; Hsing Wu et al., 2013), triability (Moore and Benbasat, 1991; Hsing Wu et al., 2013) and observability (Karahanna et al., 1999) are taken almost directly from the respective source. Furthermore, the organizational questions are also based on existing literature. Organizational readiness (Lokuge et al., 2019), organizational size (Wang et al., 2010) and senior management support (Sharma et al., 2008; Wang et al., 2010) is again taken almost identically from the respective source. Organizational age is self-explanatory and therefore measured by the number of years the company exists. However, we were not able to find academic sources for our environment questions. This is due to the fact that there is no established "business ecosystem" theory which can be used as an underlying concept. Additionally, defining the environment context contains subjective and individual aspects and therefore such questions can not be easily taken from other research. Therefore, based on the theoretical conceptualisation of the hypothesis, competition intensity is assessed through the perceived market growth, pressure is defined by the perceived pressure placed by other stakeholder on one's company, regulatory uncertainty is measured by the subjective perception of (future) regulatory support for blockchain, collaboration is given by the collaboration with other stakeholders and the scope of the ecosystem results from the number of customers and suppliers and the number of countries they operate in.

\subsection{Data Collection}

To reach more participants, the survey was offered in English and German. The targeted population were employees from C-level and management across all industries. Geographically, we focused on the DACH-region which consists of Germany (D), Austria (A) and Switzerland (CH). We were able to acquire 205 participants in Germany, 75 participants in Austria, and 70 participants in Switzerland. This lead to a total amount of 350 participants. The time range for participation was from November 3, 2020 till March 19, 2021.

\subsection{Data Analysis}

In order to assess our survey, we used the Python scripting language. A link to the entire code, the survey questions as well as the anonymous dataset are provided at the end of the paper. The assessment of the results happened in three steps. First, in order to calculate the internal consistence of our questions we used the Cronbach Alpha. A value should be greater than 0.7 in order to be acceptable (Cortina, 1993). Secondly, we calculated the correlation. Since our scale is ordinal, we used the Spearman rank correlation. It describes the relationship of two variables through a monotonic function (Artusi et al., 2002). According to Akoglu (2018) a value of 0.2 is weak, a value of 0.3 is moderate, a value between 0.4 and 0.6 is strong and everything above 0.6 is seen as very strong. This logic can obviously be applied for the negative values of the scale, too. Third, to test our BAM we performed a binary logistic regression analysis. In contrast to other regressions, the binary logistic regression has a binary (yes vs no, zero vs one) dependent variable. Our analysis' dependent variable is the variable "blockchain adoption". Participants were directly asked, in which stage (None, Initial Exploration, Proof of Concept, Trial, In-production, Stopped) their blockchain project is. We summarized the different categories to obtain a robust measure for adoption: "None" equals to no adoption (or a zero) and the other stages equal to an adoption (or to an one). The coefficents $\beta$ of the binary logistic regression by which factor an increase of the independent variable by one unit changes the odds of the dependent variable. Our final model is formulated as follows:

$$
\begin{aligned}
\text { Tech }= & \beta_{1} \text { rel_ad } v+\beta_{2} \text { cmptblty }+\beta_{3} \text { cmplxty }+\beta_{4} \text { trblty } \\
& +\beta_{5} \text { obsvblty } \\
\text { Orga }= & \beta_{6} \text { org_rness }+\beta_{7} \text { org_size }+\beta_{8} \text { sen_mngm }+\beta_{9} \text { org_yrs }
\end{aligned}
$$


TABLE 2 | Sources for the survey questions.

Source

$\mathrm{Nr}$. of questions

Relative Advantage (rel_adv)

Hsing Wu et al. (2013)

Compatability (cmptblty)

Moore and Benbasat (1991)

Wang et al. (2010)

Moore and Benbasat (1991)

Hsing Wu et al. (2013)

3

Wang et al. (2010)

Hsing Wu et al. (2013)

Trialability (trblty)

Moore and Benbasat (1991)

Karahanna et al. (1999)

Lokuge et al. (2019)

Organizational Readiness (org_rness)

Wang et al. (2010)

Sharma et al. (2008)

Wang et al. (2010)

Defined by authors

Defined by authors

Defined by authors

Defined by authors

Defined by authors

Defined by authors

$$
\begin{aligned}
\text { Env }= & \beta_{10} \text { comp_intsty }+\beta_{11} \text { pressure }+\beta_{12} \text { reg_unctnty }+\beta_{13} \text { collab } \\
& +\beta_{14} \text { scope_eco }
\end{aligned}
$$

Blockchain_Adoption $=\beta_{0}+\beta_{c} b c \_k n w l d g+T e c h+$ Orga + Env

\section{FINDINGS}

\subsection{Descriptive Statistics}

Figure A1 in the appendix shows the answers of each subquestion. One can observe that the tendency for all constructs tends to be positive. The perceived pressure and the perceived complexity show that more people tend to disagree with the asked questions. Nevertheless, by putting those answers into context, we realize that the respondents do not think there is pressure being placed on them to adopt blockchain and that they do not perceive the technology as complex.

As shown in Figure 2, we see that most of the respondents of our survey work in the ICT industry (41), followed by health (35), health and social industry (35) and manufacturing (35). Agriculture (7) and pharmaceutical/chemistry (6) are represented the least. Figure 3 shows the use case distribution. In contrast to the other questions, the participants had the option to select no use case or multiple use cases and therefore the total number of use cases exceed the total number of participants. Most projects are focused on trading (63), certification (59) and track and trace (57), whereas trade finance (19) and fund management (14) are the least chosen cases. The distribution of blockchain roles in Figure 4 show clearly that most respondents see themselves as application users (158), with a sharp fall to the second role being technology advisor (56). The distribution of the current blockchain stage (Figure 5) show that most companies (146) do not have any blockchain project in their company.

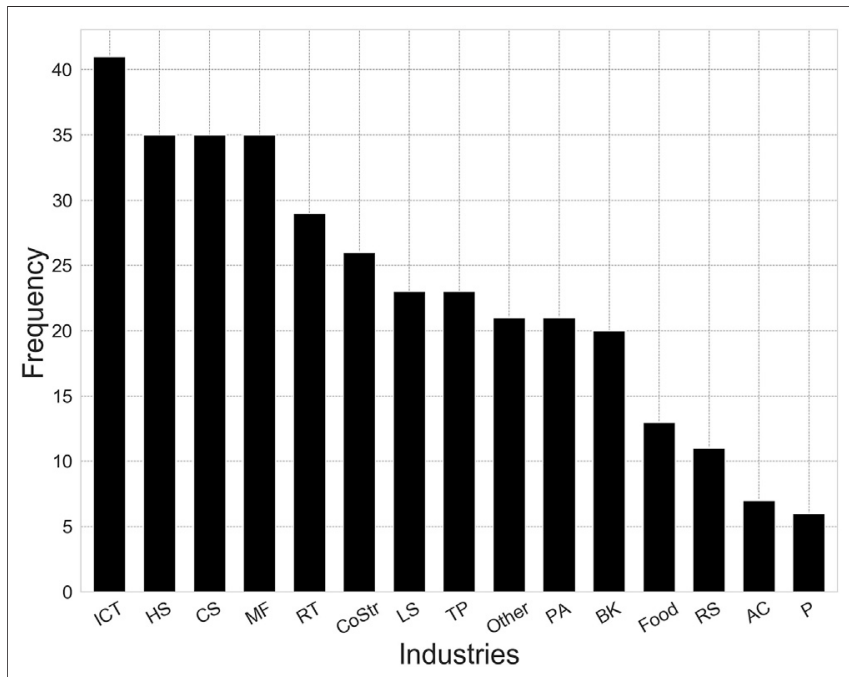

FIGURE 2 | Distribution of industries.

However, if we sum up all the other stages such as "PoC", "initial exploration", "in production" and "trial/pilot", 192 of the enterprises have a blockchain project. It is also visible that only eight companies stopped their ambitions.

The distribution of blockchain stages withing industries is shown in Table 3. Almost every sector's most-mentioned stage is "None". Nevertheless, it must be pointed out that there are plenty of enterprises (especially in the consultancy and public administration sector) exploring the technology. Certain areas such as banking, consultancy, construction, ICT, leisure, manufacturing and retail seem to have many projects in production stage. In total, there are more projects being in production than in the trial stage. Particularly in the ICT sector, most projects are in production. Looking at the overall distribution per sector, it is observable that some sectors, e.g. the 


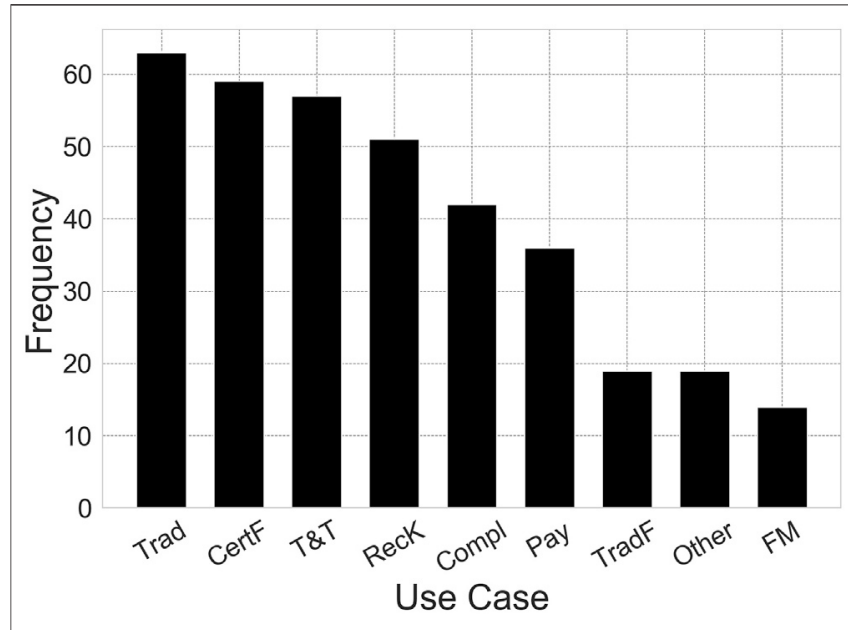

FIGURE 3 | Distribution of use cases.

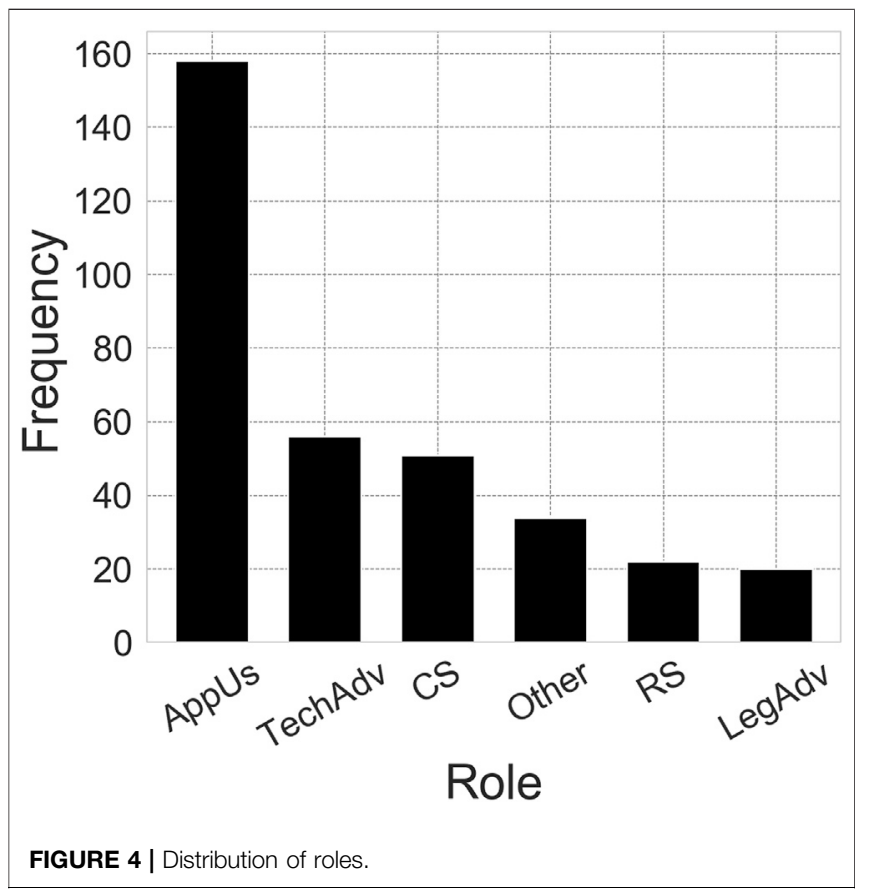

banking sector, have an almost uniform distribution, whereas others, e.g. the food sector, are heavily skewed towards "None". At last it is notable, that only a few project that were stopped.

In Table 4, we state the Cronbach alphas of our constructs. All the constructs, except the competition intensity, have a Cronbach alpha of at least 0.7 or higher. However, since there is no universal value for a good Cronbach alpha and since competition intensity is very close to the previously set threshold, we decided to still include it in our research. The correlations are shown in Table 5. We see that the entire technology context highly correlates $(>0.4)$ with the blockchain stage. The highest correlation can be observed with the observability. The organizational constructs seem to

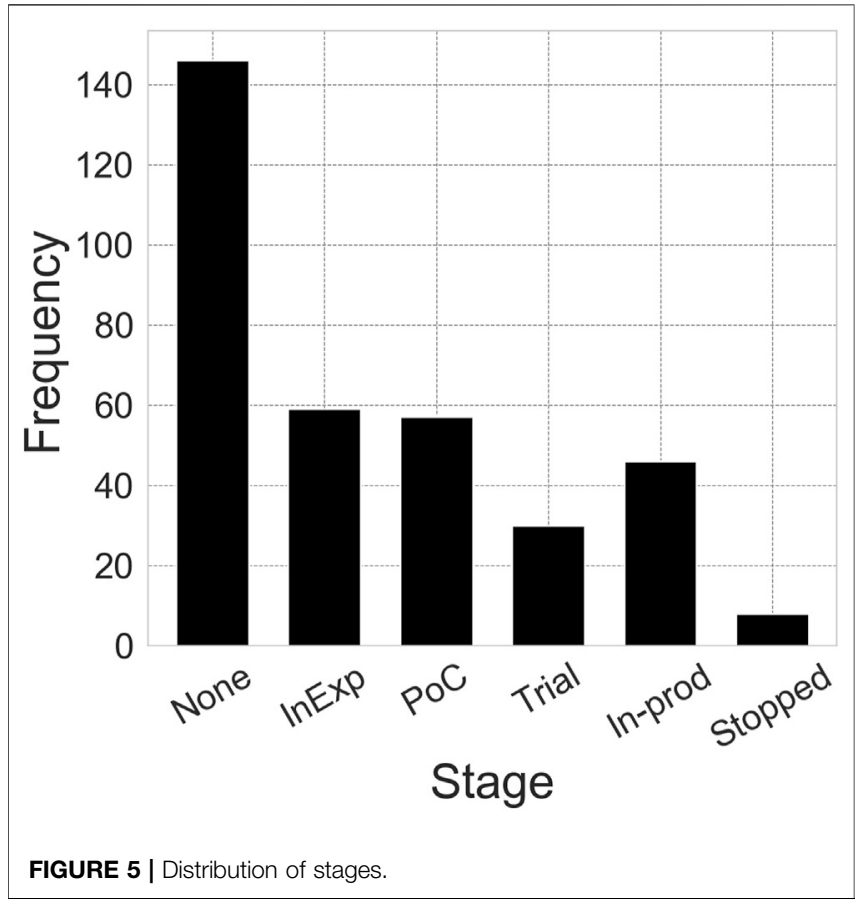

be split in two groups. On one hand the number of full-time employees and organizational age do not correlate with the blockchain stage. On the other hand, organizational readiness and senior management support correlate strongly with the stage. The environment sector's constructs have the lowest correlation factors on average. Only collaboration, competition intensity and pressure are slightly above the threshold of 0.3 , whereas the regulatory uncertainty has the lowest correlation factor, meaning there is practically no correlation between the stage of a blockchain project and the perceived regulatory uncertainty. Observing the further values gives insight on more relationships. E.g. all constructs within the technology context seem to correlate with each other, the highest one being between compatibility and relative advantage. Complexity reveals to have (aside with the organizational age) constantly negative values. Intuitively this makes sense, since for example the more complex a technology is perceived, the less likely it is to be adopted. The results of the organizational context are very heterogeneous. Organizational age and the company size seem to show no or only very weak correlations, whereas the organizational readiness and senior management support show in general high correlations. Especially the combination of those two exposes the strongest relationship within the dataset. In the environmental context, there seems to be a split as well. Regulatory uncertainty and the scope of ecosystem do not correlate with almost any other construct, while competition intensity, stakeholder pressure and collaboration reveal to have moderate and high relationships with other variables.

\subsection{Logistic Regression}

The final results of the binary logistic regression to test our BAM are shown in Table 6. The Hosmer-Lemeshow-Test shows a 
TABLE 3 | Distribution of blockchain stage within industry.

\begin{tabular}{|c|c|c|c|c|c|c|c|}
\hline & None & InExp & PoC & Trial & In-prod & Stopped & Tota \\
\hline $\mathrm{ICT}$ & $17.10 \%$ & $7.30 \%$ & $26.80 \%$ & $12.20 \%$ & $31.70 \%$ & $4.90 \%$ & 41 \\
\hline Consultancy & $40.00 \%$ & $25.70 \%$ & $17.10 \%$ & $2.90 \%$ & $11.40 \%$ & $2.90 \%$ & 35 \\
\hline Health and Social & $51.40 \%$ & $20.00 \%$ & $11.40 \%$ & $8.60 \%$ & $5.70 \%$ & $2.90 \%$ & 35 \\
\hline Manufacturing & $45.70 \%$ & $14.30 \%$ & $22.90 \%$ & $5.70 \%$ & $11.40 \%$ & $0.00 \%$ & 35 \\
\hline Retail & $51.70 \%$ & $17.20 \%$ & $6.90 \%$ & $6.90 \%$ & $10.30 \%$ & $6.90 \%$ & 29 \\
\hline Construction & $42.30 \%$ & $11.50 \%$ & $23.10 \%$ & $3.80 \%$ & $19.20 \%$ & $0.00 \%$ & 26 \\
\hline Leisure & $65.20 \%$ & $17.40 \%$ & $0.00 \%$ & $0.00 \%$ & $17.40 \%$ & $0.00 \%$ & 23 \\
\hline Transport & $21.70 \%$ & $13.00 \%$ & $26.10 \%$ & $21.70 \%$ & $13.00 \%$ & $4.30 \%$ & 23 \\
\hline Public Administration & $52.40 \%$ & $28.60 \%$ & $9.50 \%$ & $9.50 \%$ & $0.00 \%$ & $0.00 \%$ & 21 \\
\hline Banking & $20.00 \%$ & $20.00 \%$ & $20.00 \%$ & $15.00 \%$ & $25.00 \%$ & $0.00 \%$ & 20 \\
\hline Food & $76.90 \%$ & $0.00 \%$ & $7.70 \%$ & $0.00 \%$ & $7.70 \%$ & $7.70 \%$ & 13 \\
\hline Research & $27.30 \%$ & $18.20 \%$ & $27.30 \%$ & $18.20 \%$ & $9.10 \%$ & $0.00 \%$ & 11 \\
\hline Agriculture & $28.60 \%$ & $28.60 \%$ & $28.60 \%$ & $14.30 \%$ & $0.00 \%$ & $0.00 \%$ & 7 \\
\hline Pharma & $33.30 \%$ & $16.70 \%$ & $16.70 \%$ & $16.70 \%$ & $16.70 \%$ & $0.00 \%$ & 6 \\
\hline Other & $61.90 \%$ & $23.80 \%$ & $4.80 \%$ & $9.50 \%$ & $0.00 \%$ & $0.00 \%$ & 21 \\
\hline Total & 146 & 59 & 57 & 30 & 46 & 8 & 346 \\
\hline
\end{tabular}

TABLE 4 | Cronbach Alpha for each Construct.

\begin{tabular}{lcc}
\hline Construct & Cronbach alpha & Construct \\
\hline Relative advantage & 0.9020 & Senior management \\
Compatability & 0.8599 & Competition intensity \\
Complexity & 0.7909 & Pressure \\
Trialability & 0.8008 & Regulatory uncertainty \\
Observability & 0.8458 & Collaboration \\
Organizational readiness & 0.9218 & Scope of ecosystem
\end{tabular}

TABLE 5 | Correlation matrix.

\begin{tabular}{|c|c|c|c|c|c|c|c|c|c|c|c|c|c|c|c|c|}
\hline & (1) & (2) & (3) & (4) & (5) & (6) & (7) & (8) & (9) & (10) & (11) & (12) & (13) & (14) & (15) & (16) \\
\hline (1) bc_stage & 1.00 & - & - & - & - & - & - & - & - & - & - & - & - & - & - & - \\
\hline (2) bc_knwldg & 0.55 & 1.00 & - & - & - & - & - & - & - & - & - & - & - & - & - & - \\
\hline (3) $\mathrm{RA}$ & 0.55 & 0.41 & 1.00 & - & - & - & - & - & - & - & - & - & - & - & - & - \\
\hline (4) cmptblty & 0.42 & 0.33 & 0.72 & 1.00 & - & - & - & - & - & - & - & - & - & - & - & - \\
\hline (5) cmplxty & -0.40 & -0.38 & -0.55 & -0.60 & 1.00 & - & - & - & - & - & - & - & - & - & - & - \\
\hline (6) trblty & 0.43 & 0.41 & 0.62 & 0.64 & -0.71 & 1.00 & - & - & - & - & - & - & - & - & - & - \\
\hline (7) obsvblty & 0.57 & 0.56 & 0.65 & 0.58 & -0.63 & 0.65 & 1.00 & - & - & - & - & - & - & - & - & - \\
\hline (8) org_rness & 0.41 & 0.41 & 0.55 & 0.60 & -0.55 & 0.55 & 0.56 & 1.00 & - & - & - & - & - & - & - & - \\
\hline (9) nrfulltime & 0.13 & 0.12 & 0.18 & 0.09 & -0.02 & 0.06 & 0.14 & 0.08 & 1.00 & - & - & - & - & - & - & - \\
\hline (10) sen_mngm & 0.40 & 0.30 & 0.55 & 0.59 & -0.51 & 0.49 & 0.49 & 0.75 & 0.01 & 1.00 & - & - & - & - & - & - \\
\hline (11) org_yrs & -0.18 & -0.18 & -0.05 & -0.12 & 0.19 & -0.12 & -0.15 & -0.13 & 0.22 & -0.17 & 1.00 & - & - & - & - & - \\
\hline (12) comp_intsty & 0.30 & 0.25 & 0.44 & 0.44 & -0.38 & 0.40 & 0.40 & 0.57 & 0.16 & 0.50 & -0.14 & 1.00 & - & - & - & - \\
\hline (13) pressure & 0.31 & 0.21 & 0.42 & 0.43 & -0.52 & 0.51 & 0.36 & 0.40 & 0.07 & 0.39 & -0.11 & 0.41 & 1.00 & - & - & - \\
\hline (14) reg_unctnty & 0.04 & -0.05 & 0.09 & 0.13 & -0.06 & 0.05 & 0.05 & 0.09 & 0.06 & 0.16 & -0.02 & 0.21 & 0.12 & 1.00 & - & - \\
\hline (15) collab & 0.34 & 0.32 & 0.44 & 0.36 & -0.39 & 0.36 & 0.45 & 0.54 & 0.29 & 0.50 & -0.03 & 0.41 & 0.34 & 0.21 & 1.00 & - \\
\hline (16) scope_eco & 0.14 & 0.09 & 0.10 & 0.09 & -0.05 & 0.05 & 0.16 & 0.09 & 0.61 & 0.05 & 0.18 & 0.16 & 0.04 & 0.06 & 0.23 & 1.00 \\
\hline
\end{tabular}

significance level of 0.205 meaning that the binary logistic regression fits our data and is therefore a valid approach. The Nagelkerke R-square is 0.595 . Looking at the significance level of our constructs, we see that relative advantage, observability, organizational age, pressure, regulatory uncertainty and scope of ecosystem have a significant $(p<0.05)$ effect on the adoption of blockchain. By looking at the odds ratio $(\operatorname{Exp}(B))$ we can draw certain conclusions. According to our BAM, from the technological context relative advantage and observability influence the decision to adopt blockchain positively. Organizational age was the only significant construct within the organizational context. The results show that it influences the adoption positively. Lastly, there were three significant constructs within the environmental context. Pressure, regulatory uncertainty and the scope of the ecosystem influence the adoption positively. Looking at the values of the 
TABLE 6 | Results of regression.

\begin{tabular}{|c|c|c|c|c|c|}
\hline Hypotheses & Construct & Regression coefficient B & Standard error & Significance & $\operatorname{Exp}(B)$ \\
\hline Constant & Konstante & -12.699 & 2.657 & 0.000 & 0.000 \\
\hline Control Variable & bc_knwldg & 1.537 & 0.273 & 0.000 & 4.649 \\
\hline $\mathrm{H} 1$ & rel_adv & 1.225 & 0.414 & 0.003 & 3.405 \\
\hline $\mathrm{H} 2$ & cmptblty & 0.438 & 0.375 & 0.243 & 1.550 \\
\hline H3 & cmplxty & 0.136 & 0.355 & 0.701 & 1.146 \\
\hline $\mathrm{H} 4$ & trblty & -0.458 & 0.337 & 0.173 & 0.632 \\
\hline H5 & obsvblty & 0.726 & 0.323 & 0.025 & 2.066 \\
\hline H6 & org_rness & -0.351 & 0.397 & 0.377 & 0.704 \\
\hline $\mathrm{H} 7$ & org_size & -0.193 & 0.182 & 0.290 & 0.825 \\
\hline $\mathrm{H} 8$ & sen_mngm & 0.431 & 0.299 & 0.150 & 1.538 \\
\hline H9 & org_yrs & -0.526 & 0.230 & 0.022 & 0.591 \\
\hline $\mathrm{H} 10$ & comp_intsty & 0.031 & 0.257 & 0.904 & 1.032 \\
\hline $\mathrm{H} 11$ & pressure & 0.599 & 0.221 & 0.007 & 1.820 \\
\hline $\mathrm{H} 12$ & reg_unctnty & 0.489 & 0.240 & 0.042 & 1.630 \\
\hline $\mathrm{H} 13$ & collab & 0.001 & 0.328 & 0.998 & 1.001 \\
\hline $\mathrm{H} 14$ & scope_eco & 0.529 & 0.244 & 0.030 & 1.698 \\
\hline
\end{tabular}

log odds, one can observe that in our BAM the strongest impact originates from the perceived relative advantage, whereas the organizational age has the lowest impact. For the other proposed factors in our BAM, results showed no support for an influence on blockchain adoption. In order to see if there are differences between the different roles (application users vs. not application users) or the different countries (Germany vs. Switzerland vs. Austria), we split the data sample accordingly. However, we were not able to find significant changes.

\section{DISCUSSION}

\subsection{Factors Influencing Blockchain Adoption}

Our analysis identify six factors influencing the adoption of blockchain. Within the technological context, H1 (relative advantage) and H5 (observability) were confirmed by the regression, meaning that relative advantage and observability have a positive influence on blockchain adoption. These findings go along with Rogers (2003), who determined that those two factors influence innovation in general. We explain the significant positive effect of the relative advantage with the fact that the introduction of blockchain in organizations will incur certain costs. Therefore, the decision to adopt blockchain despite their costs only happens, if the perceived benefits can cover them and hence a positive relative advantage results. However, estimating the relative advantage of an innovation is difficult. In the case of blockchain, Dobrovnik et al. (2018) as well as Choi et al. (2020) explain that organizations experience difficulties to estimate the costs of adopting blockchain due to the inexperience and lack of knowledge of this new technology. Therefore, organizations will look for information outside the company. Hence, being able to observe blockchains directly in an external business environment or indirectly by reading reports and case studies, can allow organizations to understand the technology better and increase its adoption. In conclusion, $\mathrm{H} 1$ (relative advantage) and H5 (observability) indicate that in order to overcome the first stages of the innovation-decision process and to start implementing blockchain, organizations need mainly to understand and observe the benefit and advantages of this new innovation. Nevertheless, we were not able based on the results of our BAM to confirm the influence of compatibility, complexity and trialability and therefore can not support $\mathrm{H} 2, \mathrm{H} 3$ and $\mathrm{H} 4$. These findings go against the statements made by Drescher (2017), Clohessy and Acton (2019) and Rauchs et al. (2019). Although the insignificant results do not allow to state profound explanations, we can hypothesize that those three constructs simply represent less important factors influencing the decision in the first stages of the adoption process than relative advantage and observability. The idea of certain constructs outweighing others is also in accordance with Rogers (2003), who explains that in a scenario, where the relative advantage outweighs the complexity, organizations will still adopt the innovation even though they might believe it is complex.

Within the organizational context, we were able based on our BAM to confirm only $\mathrm{H} 9$ (organizational age). This indicates that older organizations are less likely to adopt blockchain. This finding is in accordance with the theory. Balasubramanian and Lee (2008) empirically showed that the impact of adopting innovations is higher for younger organizations than for older ones. Additionally, Knight and Cavusgil (2004) demonstrated that younger organizations use innovations as a way to break into markets and hence use innovations for strategic purposes. We reason our finding by arguing that younger organizations tend to enter a market, only if they have a sustained competitive advantage which older companies can not replicate easily. For example, currently it is very difficult for startups to enter the banking sector, since a lot of capital is needed and there are many regulations. However, using an emerging technology such as blockchain, which enables to invest into cryptocurrencies and in addition is not very regulated, offers a market opportunity for startups. In contrast, well-established organizations might not (yet) see any need to make use of the new technology, since their current business model works well. The lack of regulation and the 
sudden emergence of the technology might seem unappealing and represent a risk rather than an asset. However, this indicates also a certain threat for incumbent as they might miss the development of a new technology which could one day disrupt their current business model. The hypotheses H6 (organizational readiness), $\mathrm{H} 7$ (organizational size), and H8 (top management support) could not be confirmed. This goes against the arguments made by Clohessy and Acton (2019), who argue, based on qualitative research, that organizational readiness, organizational size and top management support influence blockchain adoption. Nevertheless, our quantitative results within the BAM could not find support for these arguments. These apparent contradictory results are still surprising and will be discussed in more depth in the next chapter.

In the environmental context, we could see based on our BAM that our hypotheses H11 (external stakeholder pressure), H12 (regulatory uncertainty) and H14 (scope of business ecosystem) were confirmed. In accordance with H11, external stakeholder pressure indeed affects the adoption positively, which matches the claims of Iacovou et al. (1995), who stated that a stakeholder can impose new technologies on a company, as long as the stakeholder is in a superior position. In addition to this, it is very plausible that external stakeholders would impose the adoption of blockchain on another organization, since the nature of a blockchain as network technology demands that many organizations join the network in order to grasp its full potential. A practical illustration is a supply chain, which only creates the benefits of transparency and traceability, if all participants along the supply chain use the same blockchain network as the backbone for their processes (Lustenberger et al., 2020; Sternberg et al., 2020). In respect to H12, regulatory uncertainty was found to have a positive influence on the blockchain adoption. This is at the first glance a surprise as it goes against our hypothesis as well as the literature (Salmon and Myers, 2019), which assumed a negative influence. However, when we looked more closely in our data, we could see that organizations with no blockchain project do not perceive regulatory uncertainty as an adoption issue, whereas organization with a blockchain project started to see the regulatory uncertainties as a barrier for the further development of their innovation. We can therefore assume that regulatory uncertainty is not an obstacle and might be even a facilitator for the first adoption steps, because organization do not need to consider regulatory issues at the beginning of their adoption-decision process. But once a blockchain project has started, the regulatory uncertainty tends to be a more serious problem for the further development and implementation. The last construct of our BAM that shows a significant positive effect on the adoption of blockchain, was the scope of the ecosystem. Again, this goes against our initial assumption in H14 and against the hypotheses by Barnes and Xiao (2019) and findings by Holweg et al. (2005). They all based their arguments on the difficulty of integrating a technology across multiple parties. Nonetheless, based on our findings it seems that blockchain can only be successfully adopted, if the scope is big enough. As it is well known, blockchain can develop its full potential only by a large number of network participants
(Rauchs et al., 2019). Having a small number of participants using a blockchain application might lead only to high costs, which can not be justified by the few benefits. Additionally, blockchain mainly helps to overcome transparency and trust issues between unknown or little-known network participants. Especially, small ecosystems where the participants are generally well known and transparency as well as trust are rarely a problem, tend to alternative, centralised solutions, which are cheaper and easier to implement (Malešević et al., 2020). The hypotheses H10 (competition intensity) and H13 (pre-existing collaboration) of our BAM could not be supported by our results. Therefore, the findings made by Zhu et al. (2006), claiming that organizations adopt innovations to retain or gain a competitive advantage mainly in a environment of intensive competition, could not be confirmed in the case of blockchain. As for pre-existing collaboration, we were not able to confirm any influence of this factors on blockchain adoption within our BAM. A possible reason for this could be the paradox that a pre-existing collaboration makes blockchain as trust and transparency provider obsolete (Sternberg et al., 2020), whereas in an ecosystem with no pre-existing collaboration the adoption of blockchain will be difficult due to a lake of coordination (Jacobides et al., 2018). Hence, this "collaboration-paradox" might lead to a situation, where the factor "pre-existing collaboration" has an ambiguous influence on blockchain adoption.

\subsection{Ecosystem Readiness}

In the literature, many researchers have specifically highlighted the importance of the technological and organizational factors influencing the adoption of blockchain (Clohessy and Acton, 2019; Lacity and Khan, 2019; Queiroz and Fosso Wamba, 2019; Choi et al., 2020). Even though, we could find support for some technological (relative advantage, observability) and organizational factors (organizational age), our results from our Blockchain Adopation Model suggest that the important factors influencing the adoption of blockchain are mainly given by an organization's environment rather than by the technology or the organization itself. This might be not surprising, then as others have already stated (Barnes and Xiao, 2019; Sternberg et al., 2020), blockchain is an inter-organizational technology which cannot create benefits if implemented by one organization alone. Furthermore-and in contrast to other interorganizational technologies like EDI (Iacovou et al., 1995)blockchain develops its full potential only if adopted within a large business network, which can be also defined as the business ecosystem. Based on our BAM we can thereby hypothesize three main business ecosystem attributes that influence the blockchain adoption: first, there must be at least one stakeholder in the ecosystem putting pressure on the others to adopt blockchain; second, the ecosystem needs to be large for a blockchain creating sufficient benefit; and third, the ecosystem needs to be capable establishing regulatory certainty for developing the blockchain adoption further.

In our opinion, these three attributes could further contribute to overcome the existing paradoxical tensions in blockchain adoption (Sternberg et al., 2020). We summarized this as the 
"collaboration-paradox", suggesting that blockchain cannot be successfully implemented without pre-existing interorganizational collaboration, while at the same time this preexisting inter-organizational collaboration reduces the value of blockchain to provide transparency and trust. However, in the light of our findings this "collaboration-paradox" can be resolved by a powerful ecosystem stakeholder that takes the lead in investing into the adoption of blockchain, thereby not only demonstrating the benefits and facilitating the adoption for the other ecosystem participant but also putting pressure on them to follow his path and establishing some regulatory certainty. This need for an ecosystem leader would also align with current business ecosystem literature, which states that usually one or more central organization orchestrate innovation (Jacobides et al., 2018). Likewise Rauchs et al. (2019) conclude in their survey that more than 70 per cent of all blockchain ecosystems have originated from the initiative of a single leader.

Based on this reasoning and our research findings, we would therefore propose the new idea of "ecosystem readiness" as an important factor for the adoption of blockchain. Ecosystem readiness is characterized by the following attributes: 1) a large ecosystem scope, 2) stakeholders that are not yet collaborating in a trustful and regulated environment, and 3) a powerful organization leading the ecosystem. This powerful organization further intentionally promotes innovation by 4) making the benefits of this new technology observable for others, by 5) putting pressure on the other ecosystem participants to adopt the new technology, and eventually by 6) striving for regulatory certainty in the application and use of blockchain.

In the light of our findings, we can assume that the often discussed low rate of blockchain adoption in organizations is owed to the low ecosystem readiness. We would therefore suppose that especially in larger ecosystem, widely accepted ecosystem leaders, which are actively promoting and enforcing the adoption of blockchain, are missing. From our perspective, it would be therefore recommendable to first analyse the ecosystem with the aim to study the "ecosystem readiness" before starting any blockchain project. The main focus should thereby be the identification and establishment of an ecosystem leader that is willing to lead the innovation and has the power to enforce the adoption and to establish regulations in a wider ecosystem. Furthermore, associations and universities may temporarily take over this role to promote and trigger new blockchain projects.

\section{CONCLUSION}

The three main objectives of this study are 1) a literature-based identification of potential factors that affect the adoption of blockchain technology (RQ1), 2) to state in which sense these factors affect the decision to adopt blockchain technology in organizations (RQ2) and 3) to explain the low adoption rate in organizations (RQ3). Despite a shortage of available studies, this paper recognized findings from several available scholars and identified as answer on the first research question 14 factors influencing the adoption of blockchain. Using the TOEframework it was possible to categorize the identified factors into three different contexts (technological, organizational, environmental). Furthermore, the literature allowed us to answer the second research question by formulating a Blockchain Adoption Model (BAM) based on the 14 factors and hypothesizing the influences of each of these factors as either positive or negative. After conducting a survey to test our model, we conclude that the relative advantage and observability are the technological factors influencing the adoption positively. Within the organizational context we found that in our BAM only the organizational age has a (negative) effect on the adoption. Analyzing the environmental context, we identified external stakeholder pressure, regulatory uncertainty and the scope of ecosystem as the three factors in our BAM influencing the adoption positively. In respect to our third research question, we could identify "ecosystem readiness" as the main explanation for the low adoption rate in organizations. According to our findings, an ecosystem need to have some specific attributes to adopt blockchain successfully. First, the ecosystem is large enough, second, at least one stakeholder in the ecosystem is exerting pressure on the other ecosystem members to adopt blockchain, and third, the ecosystem is capable to develop and enforce regulations. Especially the last two attributes are thereby in our opinion asking for a powerful ecosystem leader, who has the will and authority to develop regulations and impose the adoption within the ecosystem.

However, the establishment and exact role of such an "ecosystem leader" is an open question, which we cannot define based on our research. We would assume that this leader doesn't need necessarily to be a single organization but rather can also be a kind of ecosystem consortium. To better understand the phenomenon of "ecosystem readiness", further research is necessary. One possibility to explore the influence of "ecosystem readiness" on blockchain adoption would be to compare ecosystems with already established "ecosystem leaders" with "leaderless" ecosystems. Another option could be to analyse and compare ecosystems that have successfully adopted blockchain with ecosystems that failed in the blockchain adoption, with the aim to find evidences for their differences. Methodologically such ecosystem evaluations and comparisons could be best done by multiple case study research.

Since blockchain technology is still rapidly developing and more and more companies are exploring its potential, the actual state of adoption is difficult to assess. Broader adoption of blockchain is expected in the following five years. Therefore, we recommend conducting a longitudinal survey that captures and examines these changes. We expect, thereby, that technological differentiation among the various blockchains (e.g. private/ consortium vs. public blockchains), the business model behind these blockchains, as well as the applied blockchain governance model, play an important role in the adoption of this new technology in an industrial context. Based on that we further recommend to include in future studies the expectation of potential adopters regarding the different functionalities, the technological features, and the business and governance models to even better understand the ecosystem factors behind the adoption of blockchain. 


\section{DATA AVAILABILITY STATEMENT}

The original contributions presented in the study are publicly available. This data can be found here: The anonymised datasets can be found in the gitlab repository https://gitlab.com/zhaw zue/ecosystem-readiness.

\section{AUTHOR CONTRIBUTIONS}

The idea for this paper was conceived by all three authors. Furthermore, all three authors formulated the hypotheses,

\section{REFERENCES}

Ajibade, P. (2018). Technology Acceptance Model Limitations and Criticisms: Exploring the Practical Applications and Use in Technology-Related Studies, Mixed-Method, and Qualitative Researches. Lincoln, NE: Library Philosophy \& Practice.

Akoglu, H. (2018). User's Guide to Correlation Coefficients. Turkish J. Emerg. Med. 18, 91-93. doi:10.1016/j.tjem.2018.08.001

Angelis, J., and Ribeiro da Silva, E. (2019). Blockchain Adoption: A Value Driver Perspective. Business Horizons 62, 307-314. doi:10.1016/ j.bushor.2018.12.001

Artusi, R., Verderio, P., and Marubini, E. (2002). Bravais-Pearson and Spearman Correlation Coefficients: Meaning, Test of Hypothesis and Confidence Interval. Int. J. Biol. Markers 17, 148-151. doi:10.1177/172460080201700213

Bagozzi, R. P. (2007). The Legacy of the Technology Acceptance Model and a Proposal for a Paradigm Shift. J. Assoc. Inf. Syst. 8, 3. doi:10.17705/1jais.00122

Baker, J. (2011). "The Technology-Organization-Environment Framework," in Information Systems Theory: Explaining and Predicting Our Digital Society. Editors Y. K. Dwivedi, M. R. Wade, and S. L. Schneberger (New York: Springer), Vol. 1, 231-245.

Balasubramanian, N., and Lee, J. (2008). Firm Age and Innovation. Ind. Corporate Change 17, 1019-1047. doi:10.1093/icc/dtn028

Barnes, B. W., III, and Xiao, B. (2019). "Organizational Adoption of Blockchain Technology: An Ecosystem Perspective,” in DIGIT 2019 Proceedings Vol. 9, Available at: https://aisel.aisnet.org/digit2019/9.

Barney, J. (1991). Firm Resources and Sustained Competitive Advantage. J. Manag. 17, 99-120. doi:10.1177/014920639101700108

Baruffaldi, G., and Sternberg, H. (2018). "Chains in Chains-Logic and Challenges of Blockchains in Supply Chains," in Proceedings of the 51st Hawaii International Conference on System Sciences, Hawaii, January 3-6, 2018, 3926-3943. doi:10.24251/hicss.2018.494

Beck, R., and Müller-Bloch, C. (2017). "Blockchain as Radical Innovation: a Framework for Engaging with Distributed Ledgers as Incumbent Organization," in Proceedings of the 50th Hawaii International Conference on System Sciences, Hawaii, January 4-7, 2017, 5390-5399. doi:10.24251/ hicss.2017.653

Bessen, J. (2002). Technology Adoption Costs and Productivity Growth: The Transition to Information Technology. Rev. Econ. Dyn. 5, 443-469. doi:10.1006/redy.2001.0152

Bocek, T., Rodrigues, B. B., Strasser, T., and Stiller, B. (2017). "Blockchains Everywhere - a Use-Case of Blockchains in the Pharma Supply-Chain," in 2017 IFIP/IEEE Symposium on Integrated Network and Service Management (IM), Lisbon, May 8-12, 2017 (Lisbon, Portugal: IEEE), 772-777. doi:10.23919/ INM.2017.7987376

Bose, R., and Luo, X. (2011). Integrative Framework for Assessing Firms' Potential to Undertake Green it Initiatives via Virtualization - A Theoretical Perspective. J. Strateg. Inf. Syst. 20, 38-54. doi:10.1016/j.jsis.2011.01.003

Budman, M., Hurley, B., Khan, A., and Gangopadhyay, N. (2019). Deloitte's 2019 Global Blockchain Survey | Deloitte Insights. Cambridge, United Kingdom: Deloitte Development LLC. Available at: https://www2.deloitte.com/content/ dam/Deloitte/se/Documents/risk/DI_2019-global-blockchain-survey.pdf. defined the questionnaire and discussed the results. Next to the many tasks performed in collaboration, some of them were done individually. ML laid the ground for the theoretical part, SM monitored the survey and analyzed the results and FS developed the methodology.

\section{ACKNOWLEDGMENTS}

We would like to express our sincere thanks to Boryn Wojciech for his help during the theoretical part of this paper.

Carson, A., Romanelli, G., Walsh, P., and Zhumaev, A. (2018). Blockchain Beyond the Hype: What Is the Strategic Business Value. New York, NY: McKinsey \& Company, 1-13. doi:10.23943/princeton/9780691181769.001.0001

Choi, D., Chung, C. Y., Seyha, T., and Young, J. (2020). Factors Affecting Organizations' Resistance to the Adoption of Blockchain Technology in Supply Networks. Sustainability 12, 8882. doi:10.3390/su12218882

Christensen, C. M. (2013). The Innovator's Dilemma: When New Technologies Cause Great Firms to Fail. Boston, MA: Harvard Business Review Press.

Clohessy, T., and Acton, T. (2019). Investigating the Influence of Organizational Factors on Blockchain Adoption. Imds 119, 1457-1491. doi:10.1108/IMDS-082018-0365

Clohessy, T., Acton, T., and Morgan, L. (2017). The Impact of Cloud-Based Digital Transformation on IT Service Providers. Int. J. Cloud Appl. Comput. 7, 1-19. doi:10.4018/IJCAC.2017100101

Cortina, J. M. (1993). What Is Coefficient Alpha? an Examination of Theory and Applications. J. Appl. Psychol. 78, 98-104. doi:10.1037/0021-9010.78.1.98

Creswell, J. W., and Creswell, J. D. (2018). Research Design: Qualitative, Quantitative, and Mixed Methods Approaches. fifth edition edn. Los Angeles: SAGE.

Crosby, M., Pattanayak, P., Verma, S., and Kalyanaraman, V. (2016). Blockchain Technology: Beyond Bitcoin. Appl. Innovation 2, 71.

Davis, F. D. (1985). A Technology Acceptance Model for Empirically Testing New End-User Information Systems: Theory and Results. Cambridge, MA: Massachusetts Institute of Technology. Ph.D. thesis.

Depietro, R., Wiarda, E., and Fleischer, M. (1990). The Context for Change: Organization, Technology and Environment. The Process. Technol. innovation 199, 151-175.

Deshpande, A., Stewart, K., Lepetit, L., and Gunashekar, S. (2017). Distributed Ledger Technologies/Blockchain: Challenges, Opportunities and the Prospects for Standards. Overview Rep. Br. Stand. Inst. (Bsi) 40, 40.

Distanont, A. (2020). The Role of Innovation in Creating a Competitive Advantage. Kasetsart J. Soc. Sci. 41 (1), 15-21. doi:10.1016/j.kjss.2018.07.009

Dobrovnik, M., Herold, D., Fürst, E., and Kummer, S. (2018). Blockchain for and in Logistics: What to Adopt and where to Start. Logistics 2, 18. doi:10.3390/ logistics 2030018

Dong, L., Neufeld, D., and Higgins, C. (2009). Top Management Support of enterprise Systems Implementations. J. Inf. Technol. 24, 55-80. doi:10.1057/ jit.2008.21

Drescher, D. (2017). Blockchain Basics: A Non-Technical Introduction in 25 Steps. Berkley, CA: Apress.

Garriga, M., Dalla Palma, S., Arias, M., Renzis, A., Pareschi, R., and Andrew Tamburri, D. (2021). Blockchain and Cryptocurrencies: A Classification and Comparison of Architecture Drivers. Concurrency Computat. Pract. Exper. 33, e5992. doi:10.1002/cpe.5992

Glaser, F. (2017). "Pervasive Decentralisation of Digital Infrastructures: a Framework for Blockchain Enabled System and Use Case Analysis," in Proceedings of the 50th Hawaii International Conference on System Sciences, Hawaii, January 4-7, 2017, 1543-1552. doi:10.24251/hicss.2017.186

Guo, Y., and Liang, C. (2016). Blockchain Application and Outlook in the Banking Industry. Financial Innovation 2, 1-12. doi:10.1186/s40854-016-0034-9

Hackius, N., and Petersen, M. (2017). "Blockchain in Logistics and Supply Chain: Trick or Treat? in Digitalization in Supply Chain Management and Logistics: 
Smart and Digital Solutions for an Industry 4.0 Environment," in Proceedings of the Hamburg International Conference of Logistics (HICL), Hamburg, October 12-13, 2017 (Berlin: epubli GmbH), 3-18.

Hoffmann, V. H., Trautmann, T., and Hamprecht, J. (2009). Regulatory Uncertainty: A Reason to Postpone Investments? Not Necessarily. J. Manage. Stud. 46, 1227-1253. doi:10.1111/j.1467-6486.2009.00866.x

Holotiuk, F., and Moormann, J. (2018). Organizational Adoption of Digital Innovation: The Case of Blockchain Technology. ECIS 2018 Proc. 1-16, 3537-3546. doi:10.24251/HICSS.2018.447

Holotiuk, F., Pisani, F., and Moormann, J. (2018). "Unveiling the Key Challenges to Achieve the Breakthrough of Blockchain: Insights from the Payments Industry," in Proceedings of the 51st Hawaii International Conference on System Sciences, Hawaii, January 3-6, 2018, 3537-3546. doi:10.24251/ HICSS.2018.447

Holweg, M., Disney, S., Holmström, J., and Småros, J. (2005). Supply Chain Collaboration:. Eur. Manag. J. 23, 170-181. doi:10.1016/j.emj.2005.02.008

Hsing Wu, C., Kao, S., and Lin, H. (2013). Acceptance of Enterprise Blog for Service Industry Int. Res. 23 (3), 260-297. doi:10.1108/10662241311331736

Iacovou, C. L., Benbasat, I., and Dexter, A. S. (1995). Electronic Data Interchange and Small Organizations: Adoption and Impact of Technology. MIS Q. 19, 465. doi:10.2307/249629

Iansiti, M., and Lakhani, K. R. (2017). The Truth about Blockchain Harvard Business Review. Available at: hbr.org/2017/01/the-truth-about-blockchain (accessed February 2, 2019).

Jacobides, M. G., Cennamo, C., and Gawer, A. (2018). Towards a Theory of Ecosystems. Strat Mgmt J. 39, 2255-2276. doi:10.1002/smj.2904

Janssen, M., Weerakkody, V., Ismagilova, E., Sivarajah, U., and Irani, Z. (2020). A Framework for Analysing Blockchain Technology Adoption: Integrating Institutional, Market and Technical Factors. Int. J. Inf. Manage. 50, 302-309. doi:10.1016/j.ijinfomgt.2019.08.012

Kamble, S., Gunasekaran, A., and Arha, H. (2019). Understanding the Blockchain Technology Adoption in Supply Chains-Indian Context. Int. J. Prod. Res. 57, 2009-2033. doi:10.1080/00207543.2018.1518610

Karahanna, E., Straub, D. W., and Chervany, N. L. (1999). Information Technology Adoption across Time: a Cross-Sectional Comparison of Pre-adoption and post-adoption Beliefs. MIS Q. 23, 183-213. doi:10.2307/249751

Knight, G. A., and Cavusgil, S. T. (2004). Innovation, Organizational Capabilities, and the Born-Global Firm. J. Int. Bus Stud. 35, 124-141. doi:10.1057/ palgrave.jibs.8400071

Koens, T., and Poll, E. (2018). "The Drivers behind Blockchain Adoption: The Rationality of Irrational Choices," in European Conference on Parallel Processing, Turin, Italy, August 27-31, 2018 (Springer), 535-546. doi:10.1007/978-3-030-10549-5_42

Lacity, M. (2018). Addressing Key Challenges to Making enterprise Blockchain Applications a Reality. MIS Q. Executive 17, 201-222.

Lacity, M., and Khan, S. (2019). "Exploring Preliminary Challenges and Emerging Best Practices in the Use of Enterprise Blockchains Applications," in Proceedings of the 52nd Hawaii International Conference on System Sciences, Hawaii, January 8-11, 2019, 4665-4674. doi:10.24251/hicss.2019.563

Lalic, B., and Marjanovic, U. (2010). "Organizational Readiness/Preparedness," in E-business Issues, Challenges and Opportunities for SMEs: Driving Competitiveness (IGI Global). Editors M. M. Cruz-Cunha and J. Varajão (Hershey, PA: Business Science Reference), 101-116. doi:10.4018/978-161692-880-3.ch007

Lee, G., and Xia, W. (2006). Organizational Size and IT Innovation Adoption: A Meta-Analysis. Inf. Manage. 43, 975-985. doi:10.1016/j.im.2006.09.003

Lokuge, S., Sedera, D., Grover, V., and Dongming, X. (2019). Organizational Readiness for Digital Innovation: Development and Empirical Calibration of a Construct. Inf. Manage. 56, 445-461. doi:10.1016/j.im.2018.09.001

Lustenberger, M., Spychiger, F., and Malesevic, S. (2020). "Towards a Better Understanding of the Value of Blockchains in Supply Chain Management," in Information Systems. Editors M. Themistocleous and M. Papadaki (Cham: Springer International Publishing)), 101-112. doi:10.1007/978-3-03044322-1_8

Malešević, S., Lustenberger, M., and Spychiger, F. (2020). Applying Distributed Ledger Concepts to a Swiss Regional Label Ecosystem. Logistics 4, 32. doi:10.3390/logistics4040032
Moore, G. C., and Benbasat, I. (1991). Development of an Instrument to Measure the Perceptions of Adopting an Information Technology Innovation. Inf. Syst. Res. 2, 192-222. doi:10.1287/isre.2.3.192

Moore, J. F. (1999). Predators and Prey: A New Ecology of Competition. Boston, MA: Harvard Business School Press, 121-141.

Nakamoto, S. (2008). Bitcoin: A Peer-to-Peer Electronic Cash System. Available at: https://bitcoin.org/bitcoin.pdf.

Palma, S. D., Pareschi, R., and Zappone, F. (2021). "What Is Your Distributed (Hyper)ledger? in 2021," in IEEE/ACM 4th International Workshop on Emerging Trends in Software Engineering for Blockchain, Cagliari, Italy, May 31, 2021. doi:10.1109/WETSEB52558.2021.00011

P. C. Beatty, D. Collins, L. Kaye, J.-L. Padilla, G. B. Willis, and A. Wilmot, editor. (2020). Advances in Questionnaire Design, Development, Evaluation and Testing (Hoboken, NJ: Wiley).

Penttinen, E., and Tuunainen, V. K. (2009). Assessing the Effect of External Pressure in Inter-organizational Is Adoption-Case Electronic Invoicing Workshop on E-Business. Berlin, Heidelberg: Springer, 269-278.

Piscini, E., Cotteleer, M., and Holdowsky, J. (2018). A Technical Primer on Blockchain | Deloitte Insights. Stamford, CT: Tech. rep., Deloitte.

Porter, M. E. (1980). Competitive Strategy: Techniques for Analyzing Industries and Competitors. New York: Free Press.

Post, R., Smit, K., and Zoet, M. (2018). "Identifying Factors Affecting Blockchain Technology Diffusion," in Adoption and Diffusion of Information Technology, 1-10.

Queiroz, M. M., and Fosso Wamba, S. (2019). Blockchain Adoption Challenges in Supply Chain: An Empirical Investigation of the Main Drivers in India and the USA. Int. J. Inf. Manage. 46, 70-82. doi:10.1016/j.ijinfomgt.2018.11.021

Rauchs, M., Blandin, A., Bear, K., and McKeon, S. B. (2019). 2nd Global Enterprise Blockchain Benchmarking Study. Cambridge, United Kingdom: SSRN. doi:10.2139/ssrn.3461765

Rogers, E. (2003). Diffusion of Innovations. Tech. Rep. 0743222091. New York: Free Press.

Rogers, E. M. (2010). Diffusion of Innovations. New York: Simon \& Schuster.

Salmon, J., and Myers, G. (2019). "Blockchain and Associated Legal Issues for Emerging Markets," in Fresh Ideas About Business in Emerging Markets (London, United Kingdom: IFC World Bank Group).

Sarkis, J., González-Torre, P., and Adenso-Diaz, B. (2010). Stakeholder Pressure and the Adoption of Environmental Practices: The Mediating Effect of Training. J. Operations Manage. 28, 163-176. doi:10.1016/ j.jom.2009.10.001

Schmitt, G., Mladenow, A., Strauss, C., and Schaffhauser-Linzatti, M. (2019). Smart Contracts and Internet of Things: A Qualitative Content Analysis Using the Technology-Organization-Environment Framework to Identify KeyDeterminants. Proced. Comput. Sci. 160, 189-196. doi:10.1016/ j.procs.2019.09.460

Schuetz, S., and Venkatesh, V. (2020). Blockchain, Adoption, and Financial Inclusion in India: Research Opportunities. Int. J. Inf. Manage. 52, 101936. doi:10.1016/j.ijinfomgt.2019.04.009

Sharma, A., Thomas, D., and Konsynski, B. (2008). "Strategic and Institutional Perspectives in the Evaluation, Adoption and Early Integration of Radio Frequency Identification (Rfid): an Empirical Investigation of Current and Potential Adopters," in Proceedings of the 41st Annual Hawaii International Conference on System Sciences (HICSS 2008), Hawaii, January 7-10, 2008 (IEEE), 407. doi:10.1109/hicss.2008.412

Sharpe, A., and Currie, I. (2008). Competitive Intensity as Driver of Innovation and Productivity Growth: A Synthesis of the Literature. Ottawa, Ontario: Centre for the Study of Living Standards, CSLS Research Reports.

Spychiger, F., Tasca, P., and Tessone, C. J. (2021). Unveiling the Importance and Evolution of Design Components through the "Tree of Blockchain". Front. Blockchain 3, 60. doi:10.3389/fbloc.2020.613476

Stemberger, M., Manfreda, A., and Kovačič, A. (2011). Achieving Top Management Support with Business Knowledge and Role of IT/IS Personnel. Int. J. Inf. Manage. 31, 428-436. doi:10.1016/ j.ijinfomgt.2011.01.001

Sternberg, H. S., Hofmann, E., and Roeck, D. (2020). The Struggle Is Real: Insights from a Supply Chain Blockchain Case. J. Business Logistics. doi:10.1111/ jbl.12240 
Sue, V., and Ritter, L. (2012). Conducting Online Surveys (2455 Teller Road. Thousand Oaks California 91320 United States: SAGE Publications, Inc. doi:10.4135/9781506335186

Sun, Y., Fan, L., and Hong, X. (2018). Technology Development and Application of Blockchain: Current Status and Challenges. Chin. J. Eng. Sci. 20, 27-32. doi:10.15302/j-sscae-2018.02.005

Tapscott, D., and Tapscott, A. (2016). Blockchain Revolution: How the Technology behind Bitcoin Is Changing Money, Business, and the World. New York: Penguin.

Vadgama, N., and Tasca, P. (2021). An Analysis of Blockchain Adoption in Supply Chains between 2010 and 2020. Front. Blockchain 4, 8. doi:10.3389/ fbloc.2021.610476

Venkatesh, V., Morris, M. G., Davis, G. B., and Davis, F. D. (2003). User Acceptance of Information Technology: Toward a Unified View. MIS Q. 27, 425. doi:10.2307/30036540

Vives, X. (2008). Innovation and Competitive Pressure*. J. Ind. Econ. 56, 419-469. doi:10.1111/j.1467-6451.2008.00356.x

Wang, Y.-M., Wang, Y.-S., and Yang, Y.-F. (2010). Understanding the Determinants of RFID Adoption in the Manufacturing Industry. Technol. Forecast. Soc. Change 77, 803-815. doi:10.1016/j.techfore.2010.03.006

Weiner, B. J. (2009). A Theory of Organizational Readiness for Change. Implementation Sci. 4. doi:10.1186/1748-5908-4-67

Werner, F., Basalla, M., Schneider, J., Hayes, D., and Vom Brocke, J. (2020). Blockchain Adoption from an Interorganizational Systems Perspective-A Mixed-Methods Approach.. Inform. Sys. Manag. 38 (1). doi:10.1080/ 10580530.2020.1767830

Wiersema, M. F., and Bowen, H. P. (2008). Corporate Diversification: the Impact of Foreign Competition, Industry Globalization, and Product Diversification. Strat. Mgmt. J. 29, 115-132. doi:10.1002/smj.653
Willis, G. B., and Lessler, J. T. (1999). Question Appraisal System Qas-99. Rockville, MD: National Cancer Institute, Research Triangle Institute.

Young, R., and Jordan, E. (2008). Top Management Support: Mantra or Necessity? Int. J. project Manag. 26, 713-725. doi:10.1016/j.ijproman.2008.06.001

Zhu, K., Kraemer, K. L., and Xu, S. (2006). The Process of Innovation Assimilation by Firms in Different Countries: A Technology Diffusion Perspective on E-Business. Manage. Sci. 52, 1557-1576. doi:10.1287/mnsc.1050.0487

Ziolkowski, R., Miscione, G., and Schwabe, G. (2020). Decision Problems in Blockchain Governance: Old Wine in New Bottles or Walking in Someone Else's Shoes? J. Manage. Inf. Syst. 37, 316-348. doi:10.1080/ 07421222.2020 .1759974

Conflict of Interest: The authors declare that the research was conducted in the absence of any commercial or financial relationships that could be construed as a potential conflict of interest.

Publisher's Note: All claims expressed in this article are solely those of the authors and do not necessarily represent those of their affiliated organizations, or those of the publisher, the editors and the reviewers. Any product that may be evaluated in this article, or claim that may be made by its manufacturer, is not guaranteed or endorsed by the publisher.

Copyright (๑) 2021 Lustenberger, Malešević and Spychiger. This is an open-access article distributed under the terms of the Creative Commons Attribution License (CC $B Y$ ). The use, distribution or reproduction in other forums is permitted, provided the original author(s) and the copyright owner(s) are credited and that the original publication in this journal is cited, in accordance with accepted academic practice. No use, distribution or reproduction is permitted which does not comply with these terms. 


\section{APPENDIX}

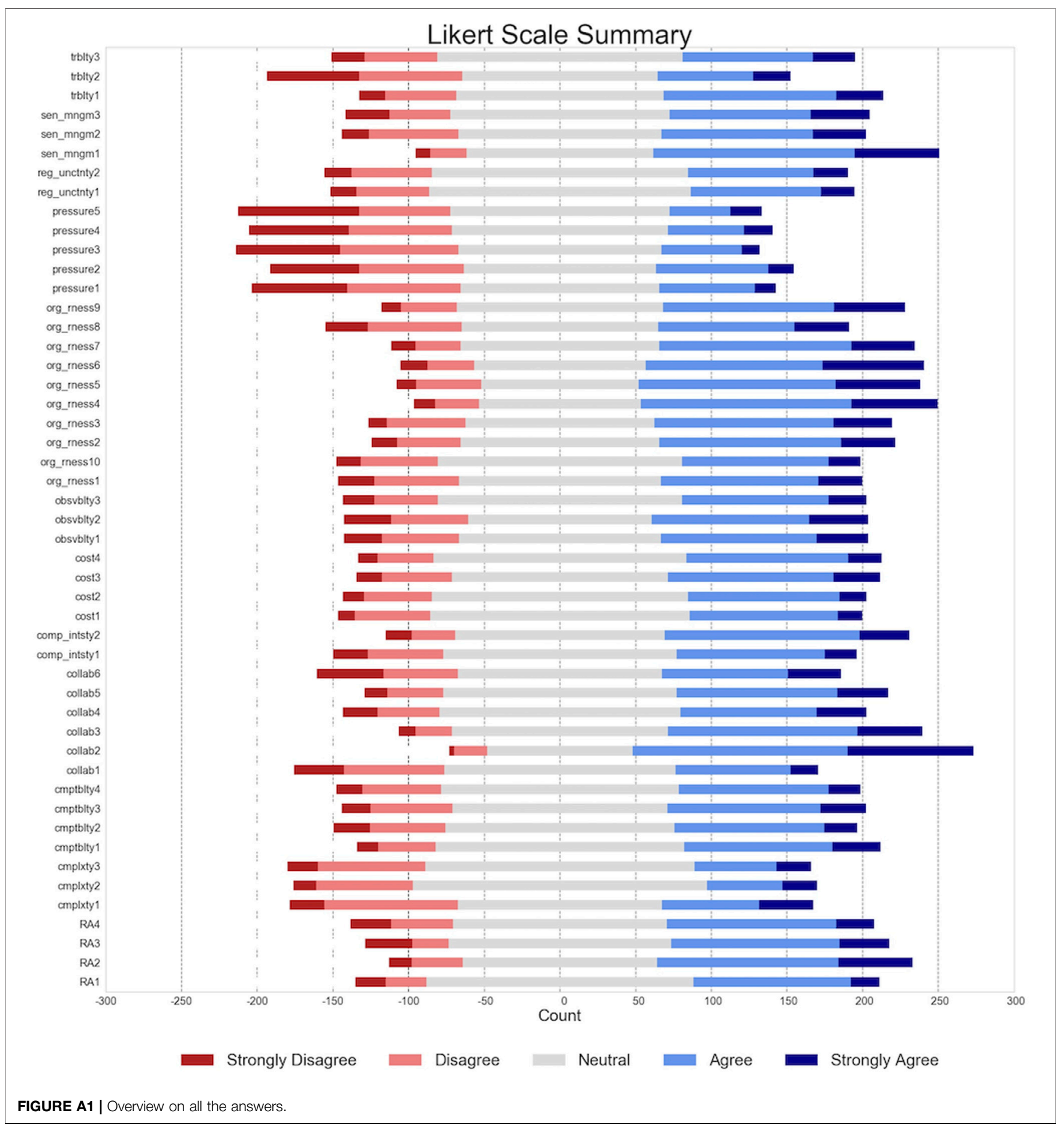

